RECEIVED UCRL-CR-122559

MAR 18 19y6

\title{
OSTI \\ Summary Report California Department of Forestry and Fire Protection Evaluation of Full-Face Air-Purifying Respirators for Wildland Fire Fighting Use
}

Prepared for the Department of Forestry and Fire Protection

Contract Number: WN-02-19-05-0

by

Donald G.Beason

James S. Johnson

Kenneth L. Foote

Lawrence Livermore National Laboratory

and

William A. Weaver

California Department of Forestry

and Fire Protection

February 1996

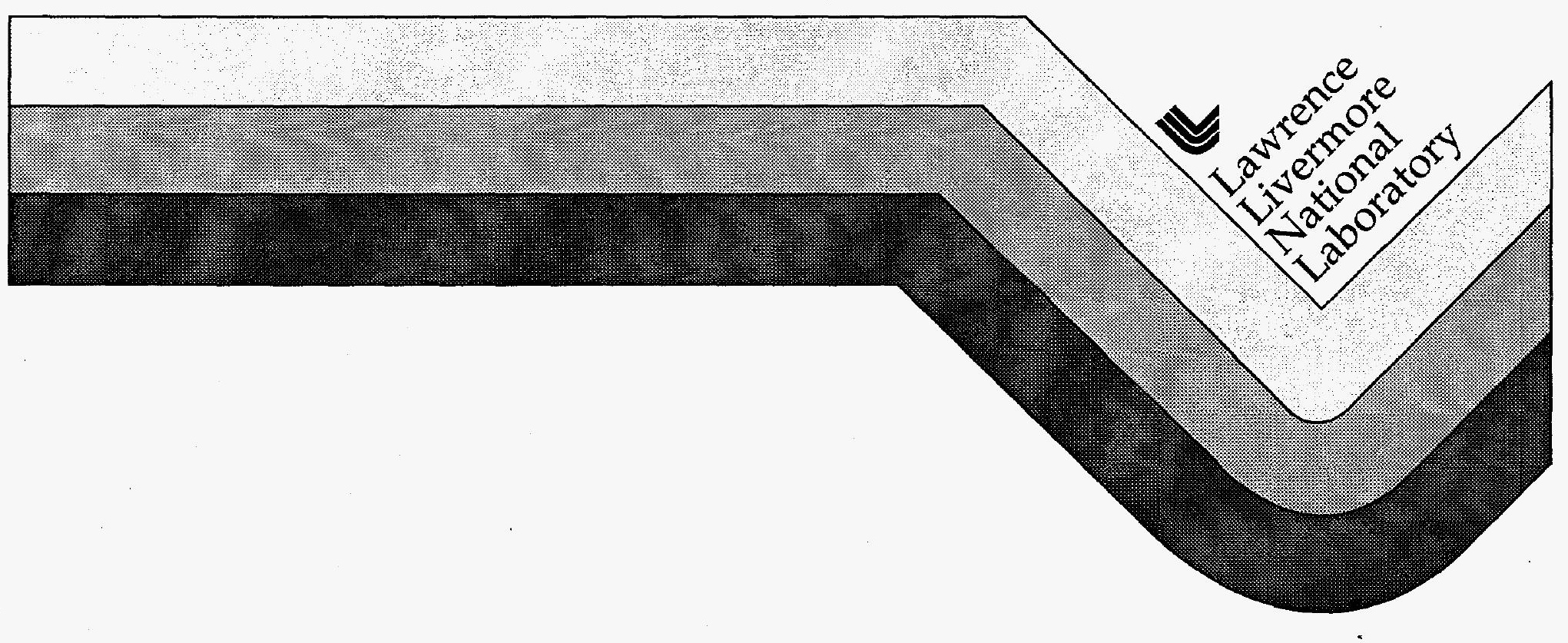




\section{DISCLAIMER}

This document was prepared as an account of work sponsored by an agency of the United States Government. Neither the United States Government nor the University of California nor any of their employees, makes any warranty, express or implied, or assumes any legal liability or responsibility for the accuracy, completeness, or usefulness of any information, apparatus, product, or process disclosed, or represents that its use would not infringe privately owned rights. Reference herein to any specific commercial products, process, or service by trade name, trademark, manufacturer, or otherwise, does not necessarily constitute or imply its endorsement, recommendation, or favoring by the United States Government or the University of California. The views and opinions of authors expressed herein do not necessarily state or reflect those of the United States Government or the University of California, and shall not be used for advertising or product endorsement purposes.

Work performed under the auspices of the U.S. Department of Energy by Lawrence Livermore National Laboratory under contract W-7405-Eng-48. 
UCRL- CR - 122559

\title{
SUMMARY REPORT \\ CALIFORNIA DEPARTMENT OF FORESTRY AND FIRE PROTECTION EVALUATION OF FULL-FACE AIR-PURIFYING RESPIRATORS FOR WILD- LAND FIRE FIGHTING USE
}

\author{
Prepared for \\ California Department of Forestry \\ and Fire Protection \\ Contract Number: WN-02-19-05-0
}

\author{
by \\ Donald G. Beason \\ James S. Johnson \\ Kenneth L. Foote \\ Lawrence Livermore National Laboratory \\ and \\ William A. Weaver \\ California Department of Forestry \\ and Fire Protection
}

February 1996 



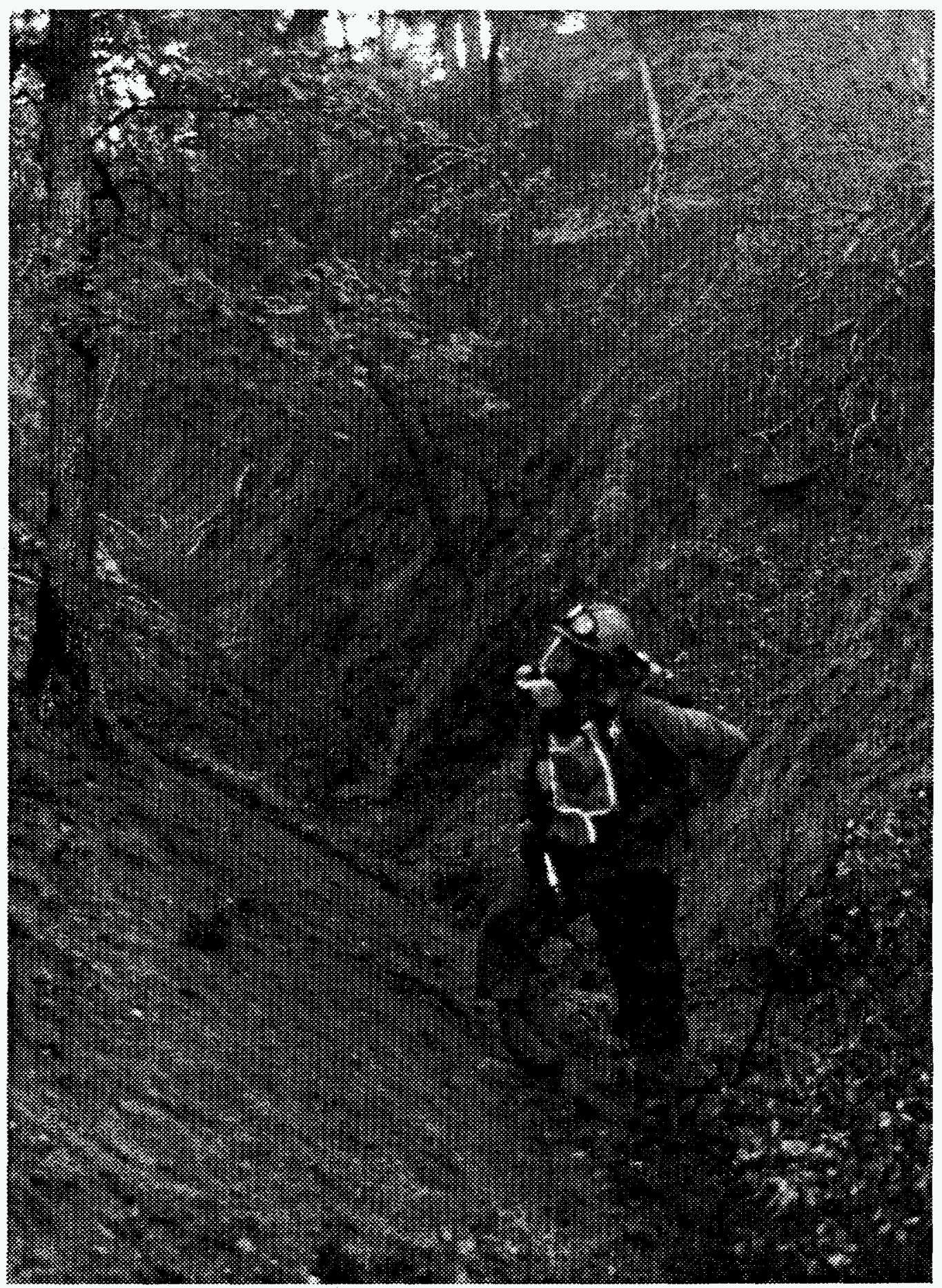

Figure 1. Fire fighter using respirator in the field. 


\title{
SUMMARY REPORT \\ CALIFORNIA DEPARTMENT OF FORESTRY AND FIRE PROTECTION EVALUATION OF FULL-FACE AIR-PURIFYING RESPIRATORS FOR WILD- LAND FIRE FIGHTING USE
}

\begin{abstract}
Wildland fire suppression personnel employed by the CDF do not currently have the equipment to protect themselves from the short-term acute affects of smoke from wildland fires. In addition, no regulations exist that specify appropriate respiratory protection and the current air-purifying respirator technology and carbon monoxide monitoring has not been adapted to fit wildland fire suppression requirements.
\end{abstract}

This three-year limited study evaluated the ability of wildland fire fighters to perform their normal job function while wearing full-face air-purifying respirators. In the first two years of this study we designed, developed and field tested a prototype "smart" air-purifying respirator which incorporated a real-time carbon monoxide monitor into a commercial full-face respirator. ${ }^{1}$ Data on carbon monoxide exposure while fighting wildland fires was collected. During the third year of this study we evaluated eight different commercially available full-face air-purifying respirators equipped with a variety of cartridges. Apparatus to aid the fire fighter in carrying the respirator and carbon monoxide personal monitor was designed and fabricated. A smoke exposure test method was developed and a laboratory study on the penetration of smoke through respirator cartridges was conducted. 
Introduction

California Department of Forestry and Fire Protection (CDF) and the Special Projects Division of Lawrence Livermore National Laboratory (LLNL) Hazards Control Department participated in a limited field evaluation of full-face air-purifying respirators in actual wildland fire responses. Information was collected from field evaluations in 1991, 1992 and 1993. This information will be utilized by CDF to help identify an air-purifying respirator that could be used daily by fire fighters for wildland fire responses.

Since the late 1980s, many organizations in the United States have initiated studies to identify the health effects of smoke on wildland fire fighters. Many of these studies have collected and evaluated enough information to suggest "remarkable" concern for the health of wildland fire fighters. In each study, the final recommendations have included the need to pursue further investigation into the problem and develop some form of respiratory protection, among many other recommendations.

With few exceptions, most of the health hazards of smoke studies conducted on wildland fire fighters have focused on fire crew activities during planned shift assignments while on major wildland fires or planned prescribed (controlled) vegetation burns. Although studies of smoke exposure during these situations are important, they represent less than five percent of the types of fires encountered by CDF wildland fire fighters.

CDF is primarily an initial attack-oriented fire control organization with an objective to extinguish 95 percent of all wildland fires within 10 acres or less. Achievement of this objective requires the maintenance of a highly mobile and poised fire control system that is capable of immediately responding to any wildland fire following the initial report. The tactical methods deployed in initial attack fire suppression are, for the most part, quite different from those applied during extended attack or major fire situations. Furthermore, initial attack tactics are not at all representative of the activities conducted during prescribed fires. 
Wildland fire initial attack methods involve direct tactical fire suppression activities where fire fighters typically perform arduous physical work at the fire line or in close parallel proximity. Some of the arduous initial attack tasks include constructing hand-cut fire line, fire engine mobile attack with a "nozzle person" on foot, and progressively extending fire hoses from a fixed water source ("progressive hose lay").

Initial attack smoke exposures often result in fire fighters being enveloped in thick acrid smoke plumes. Entrapped in this situation, fire fighters will attempt to hold their breath until a pocket of relative fresh air becomes available, which may last from a few seconds to a few minutes. Unfortunately, the involuntary physiological processes will periodically force the fire fighter to inhale before the surrounding air clears, resulting in minor to severe smoke inhalation. This situation may incapacitate the fire fighter for a period of time, ranging from minutes to days and, under severe smoke conditions, result in hospitalization.

The above concerns became the impetus for the CDF/LLNL respiratory protection development project that would hopefully provide a solution to mitigate the effects of short-term, acute exposures to wildland fire smoke. Therefore, the project was not designed to deal with the long-term smoke exposures, such as those encountered on major wildland fires where large geographic areas are filled with smoke for days or weeks.

Long-term adverse health impacts from hours, days and cumulative career exposures to smoke may have to be mitigated through other means, such as mandated safety practices, crew assignment rotations, assuring opportunities for rest in smoke-free atmospheres, etc. However, it is logical that some mitigation of any potential long-term health problems will be realized through protection from the short-term, acute smoke exposures.

During a two-week period in the summer of 1991 and a four-week period in the summer of 1992, fire fighters at CDF forest fire stations were equipped with the LLNL prototype "smart" respirators for field evaluations. In the summer of 1993 
fire fighters from six CDF forest fire stations participated in a modified evaluation program using commercially available full-face respirators. The program emphasis was changed from an integrated respirator system containing a carbon monoxide $(\mathrm{CO})$ monitor to two separate pieces of equipment. Eight manufacturers of respiratory equipment donated the air-purifying full-face respirators and associated equipment evaluated during the last year of the program. Fire fighters' exposure to $\mathrm{CO}$ was collected using commercially available personal $\mathrm{CO}$ dosimeters. A laboratory study on the penetration of smoke through typical respirator cartridges was also conducted at LLNL. ${ }^{6}$

\section{Summer of 1991}

During the summer of 1991 a CDF Helitack crew at Vina Forest Fire Station north of Chico, Ca. was selected as the initial test station. LLNL provided field staff for the duration of these experiments to collect data as well as interview fire fighters after each response. Each crew member that volunteered for the program was trained and fitted with a prototype "smart" wildland respirator that was being developed at LLNL. These respirators were modified Scott-O-Vista full-face respirators with a carbon monoxide monitor (Fig. 2) built into the inhalation manifold. Apparatus for carrying the respirator on the fire fighters was developed. Each fire fighter also carried a commercially available carbon monoxide monitor data logger for measuring and recording his $\mathrm{CO}$ exposure. During this two week period data was collected from five incidents: One control burn, two wildland fires, one car fire and one training exercise with an engine company. The data collected consisted of carbon monoxide exposure and personal comments from each fire fighter using the prototype "smart" wildland respirator. Because of the low number of fires during this two week evaluation period only limited field performance data was collected. 


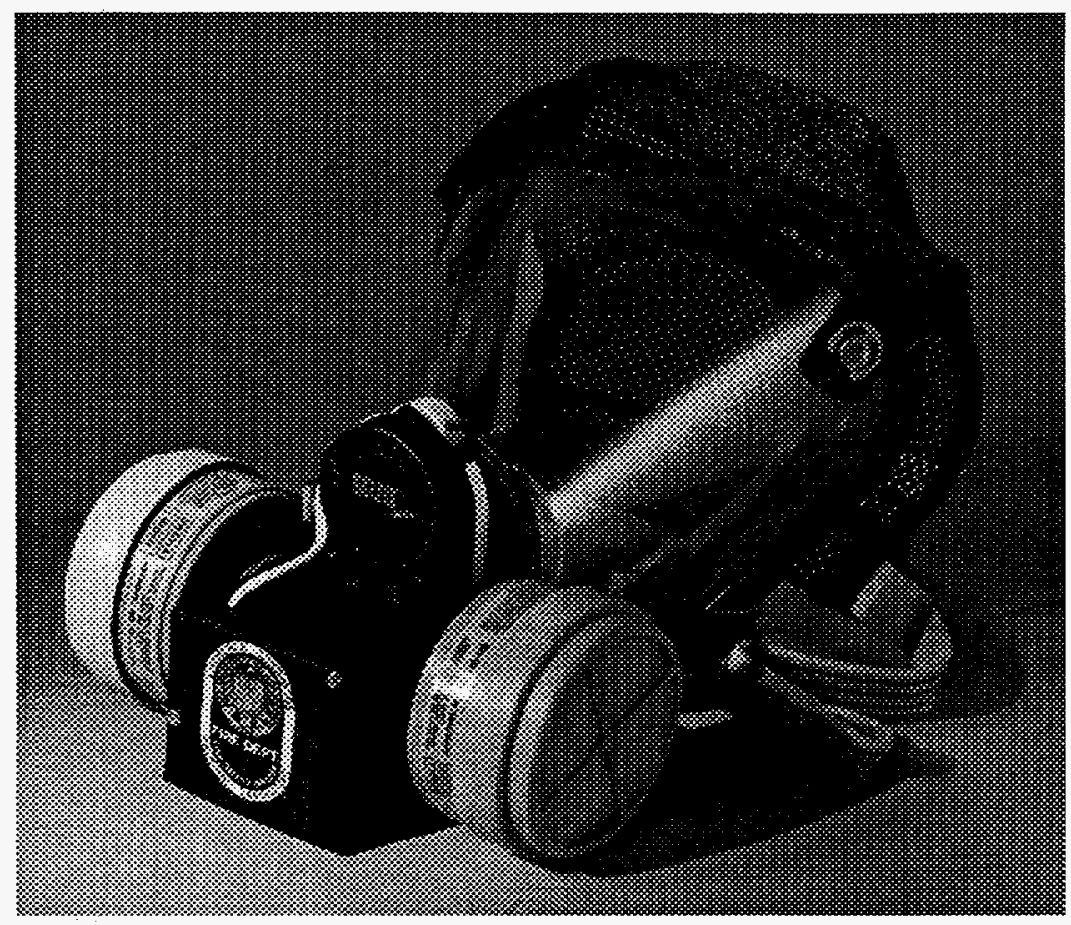

Figure 2. Prototype wildland respirator.

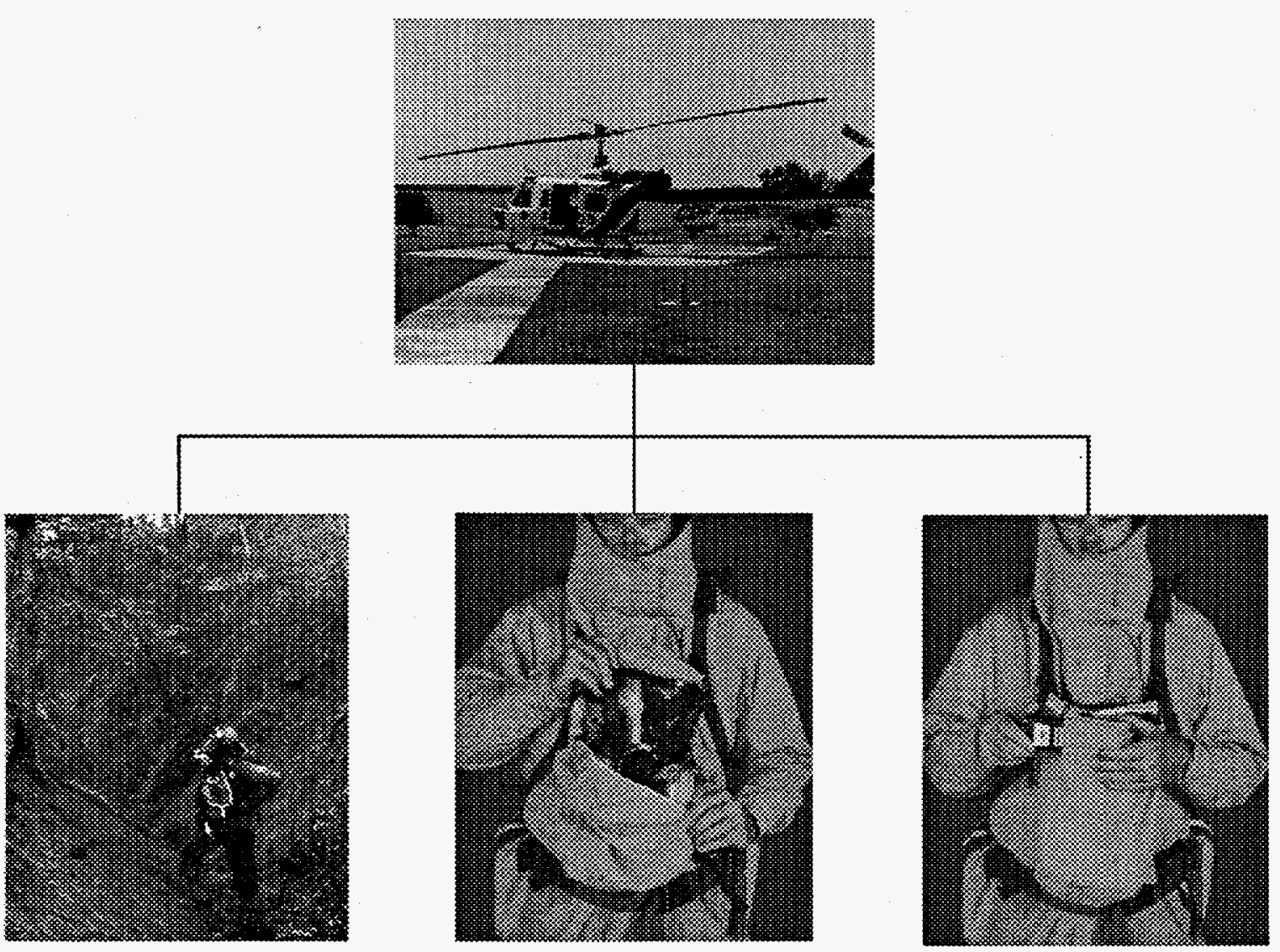

Figure 3. Helicopter, field shot, pack, close up of pack. 
In the summer of 1992 the project was moved to the Sunol Forest Fire Station at Sunol, CA. During the four-week evaluation period the prototype "smart" wildland respirators were issued to nine fire fighters and two bulldozer operators. LLNL technical personnel were also provided for this series of evaluations. The data collected consisted of carbon monoxide exposure data and personal comments from fire fighters using the "smart" wildland respirator. The personal comments were recorded on the same questionnaire used in 1991. During the four weeks spent at Sunol, there were few opportunities for the "smart" wildland respirator to be evaluated. The respirators were used extensively on only one fire. Two Sunol crews were part of a strike team on the Moccasin Flat fire (TCU 3985). The "smart" wildland respirators performance during this fire was exceptional. Several fire fighters without the respirator were unable to work at times, while those with it were able to continue to work and felt comfortable performing their job functions. 


\section{Summer of 1993}

During the summer of 1993 six CDF forest fire stations (Table 1) participated in the evaluation program. Five of the station were ground attack crews and one station was a helitack crew. Because of the lack of funds from other sources and limited funding from $\mathrm{CDF}$ for the continuation of this project it was decided to incorporate CDF station personnel into the data acquisition team. The "smart" wildland respirator used in the previous two years developed by LLNL was costly to manufacture and was only a prototype. For this reason the respirator program was expanded to evaluate a wide variety of commercially available full-face air-purifyimg respirators for wildland fire response. Manufactures of respiratory equipment were contacted requesting their participation in the study. Eight manufacturers (Appendix II) responded and agreed to supply respirators and various air-purifying cartridges at no cost to LLNL/CDF. Figures 4 through 12 are photographs of the respirators used in the 1993 evaluation program. Each respirator manufacturer sent to LLNL 16 full-face air-purifying respirators; 24 sets of combination HEPA/OV/AG, 90 sets of OV/AG/mist and 16 sets of HEPA cartridges. The placement of the initial six sets of respirators at CDF stations was made on a random basis and the remaining two sets of respirators were rotated into available stations for evaluation. The objective of this year's project focused on the evaluation of individual air-purifying respirators (as opposed to the rating of one air-purifying respirator against another) to identify the positive and negative attributes most appropriate for CDF wildland fire suppression applications. Along with the respirators all six stations were supplied carbon monoxide personal monitoring and data collection equipment. Carbon monoxide data was collected and down loaded at the end of each fire response at only three fire stations. Problems with the software and lack of in-depth training of the designated fire fighters were the main contributors to this poor collection and analysis of $\mathrm{CO}$ data. 
TABLE 1

SUMMER OF 1993 STATION LOCATIONS

\begin{tabular}{|l|c|c|c|}
\hline CDF STATION & $\begin{array}{c}\text { NUMBER OF } \\
\text { FIRE FIGHTERS }\end{array}$ & $\begin{array}{c}\text { RESPIRATOR } \\
\text { MANUFACTURE }\end{array}$ & $\begin{array}{c}\text { NUMBER OF FIRE } \\
\text { RESPONSES }\end{array}$ \\
\hline PERRIS & 11 & MSA & 7 \\
\hline DEVORE & 6 & PRO-TECH & 2 \\
\hline COARSEGOLD & 11 & DRAEGER & 17 \\
\hline PILOT HILL & 11 & CABOTT/MSA & 4 \\
\hline SUNOL & 9 & SURVIVAIR/MSA & Not recorded \\
\hline HOWARD FOREST & 11 & SCOTT & 7 \\
\hline TOTAL & 59 & & \\
\hline
\end{tabular}

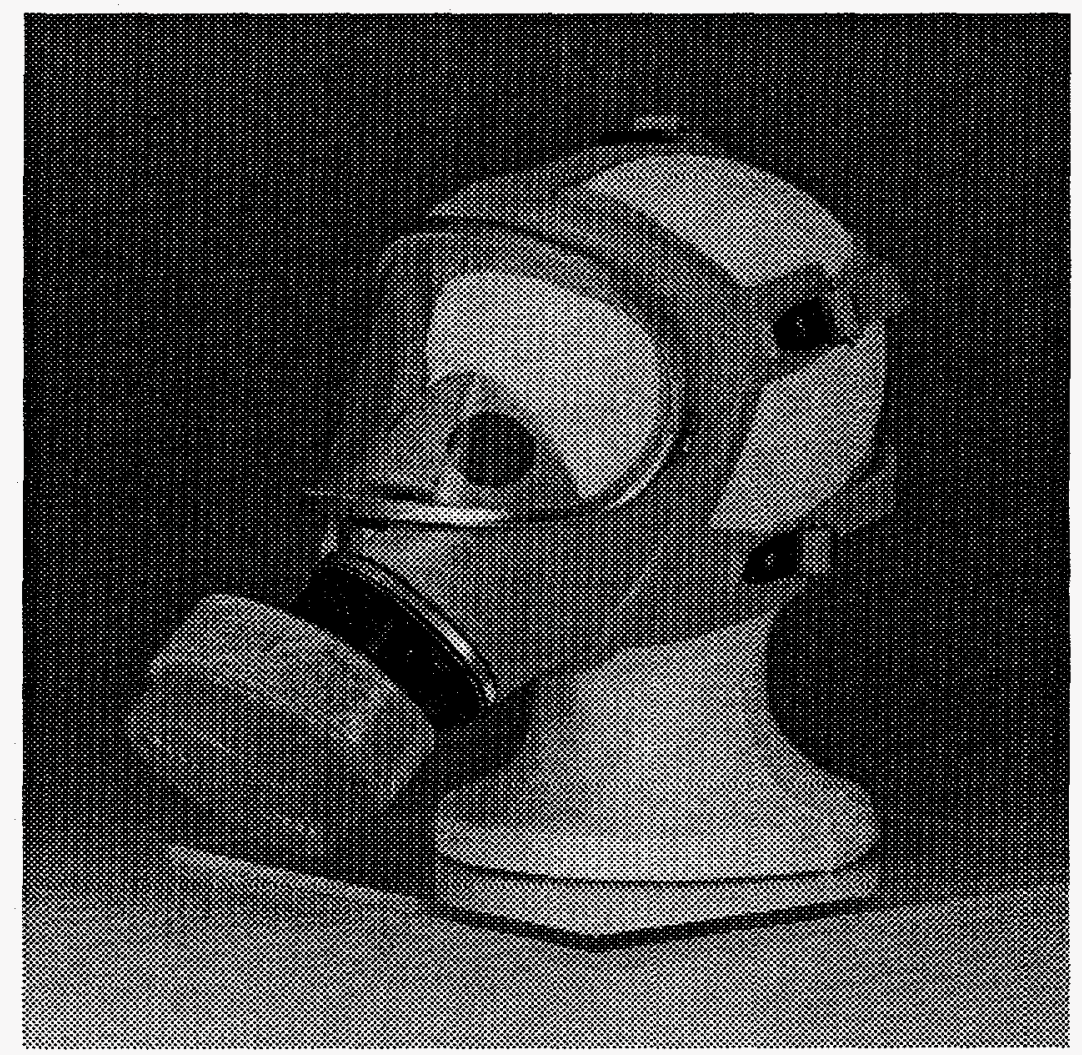

Figure 4. Draeger Model R51535 


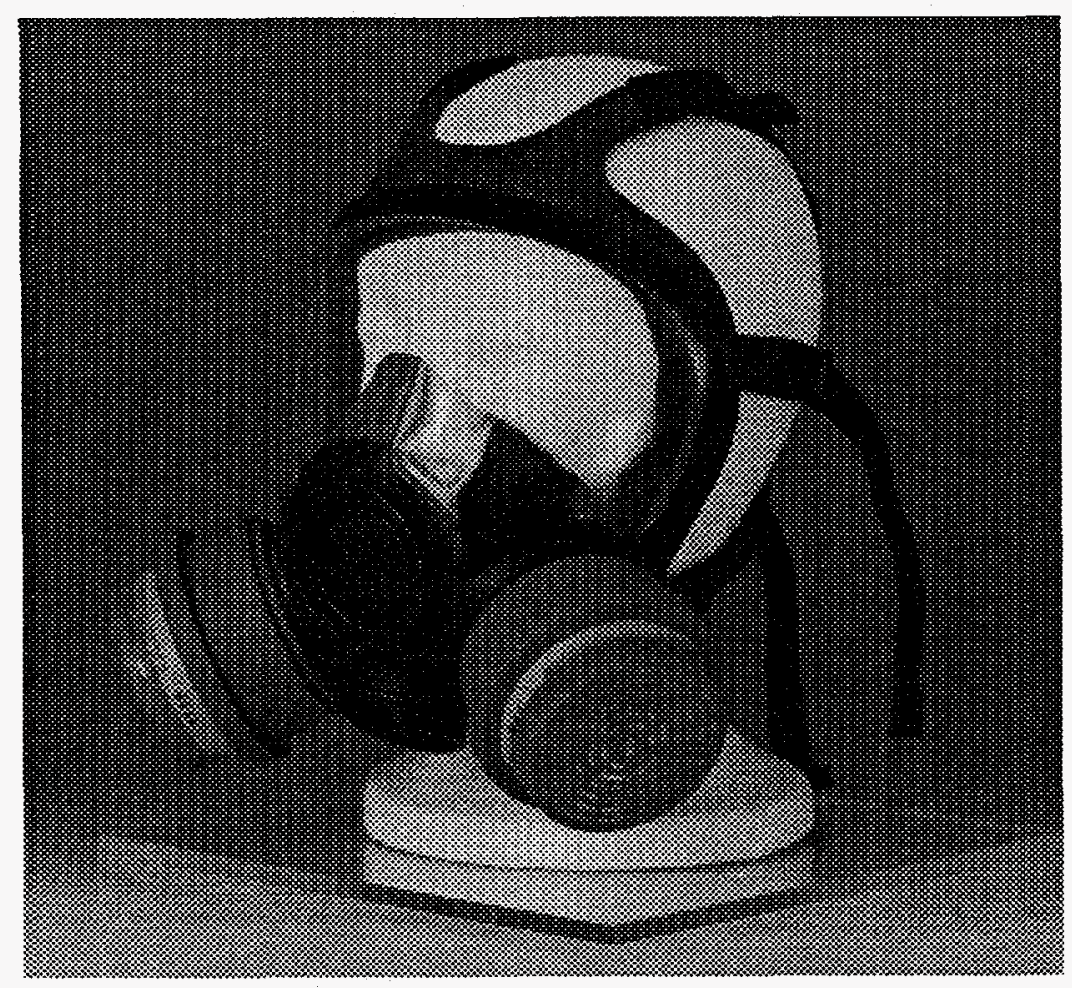

Figure 5. MSA Advantage 1000

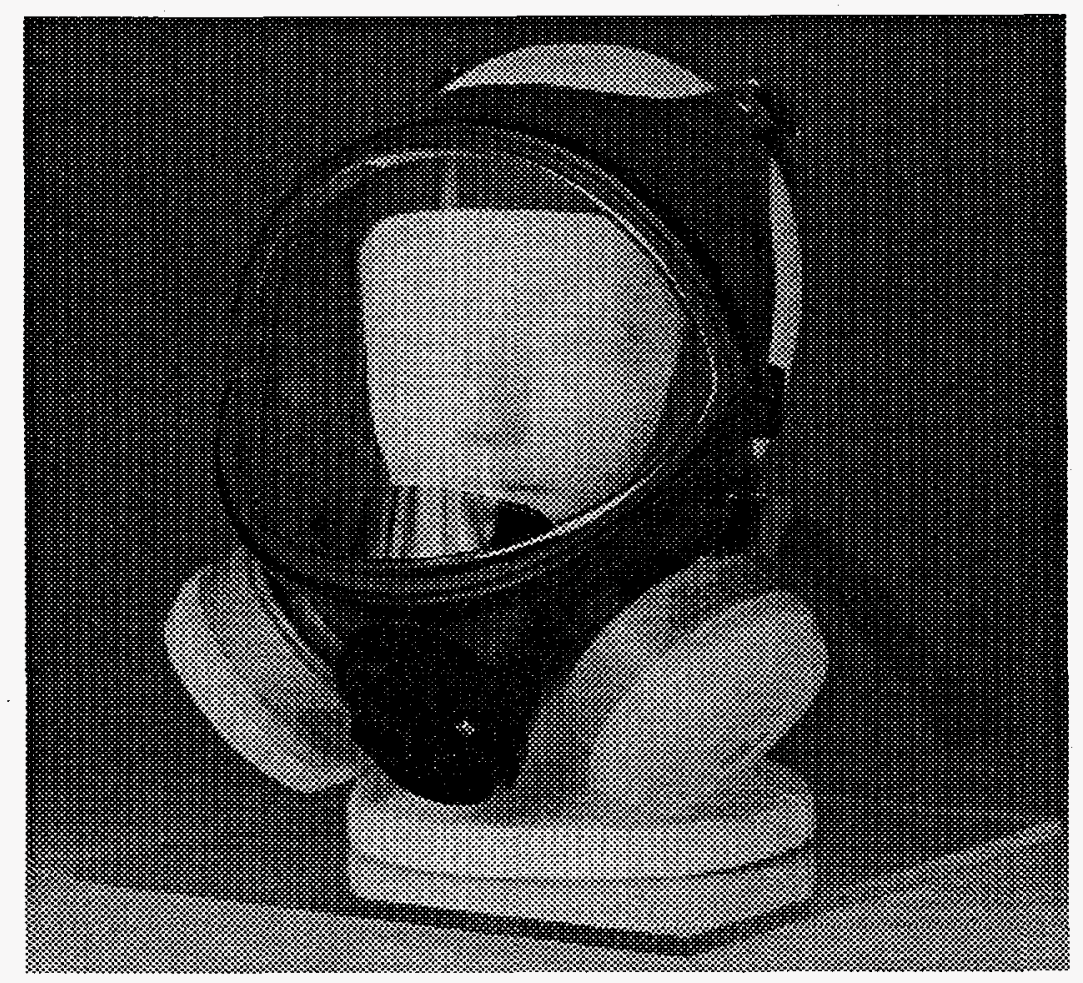

Figure 6. Survivair Model 4200-10 


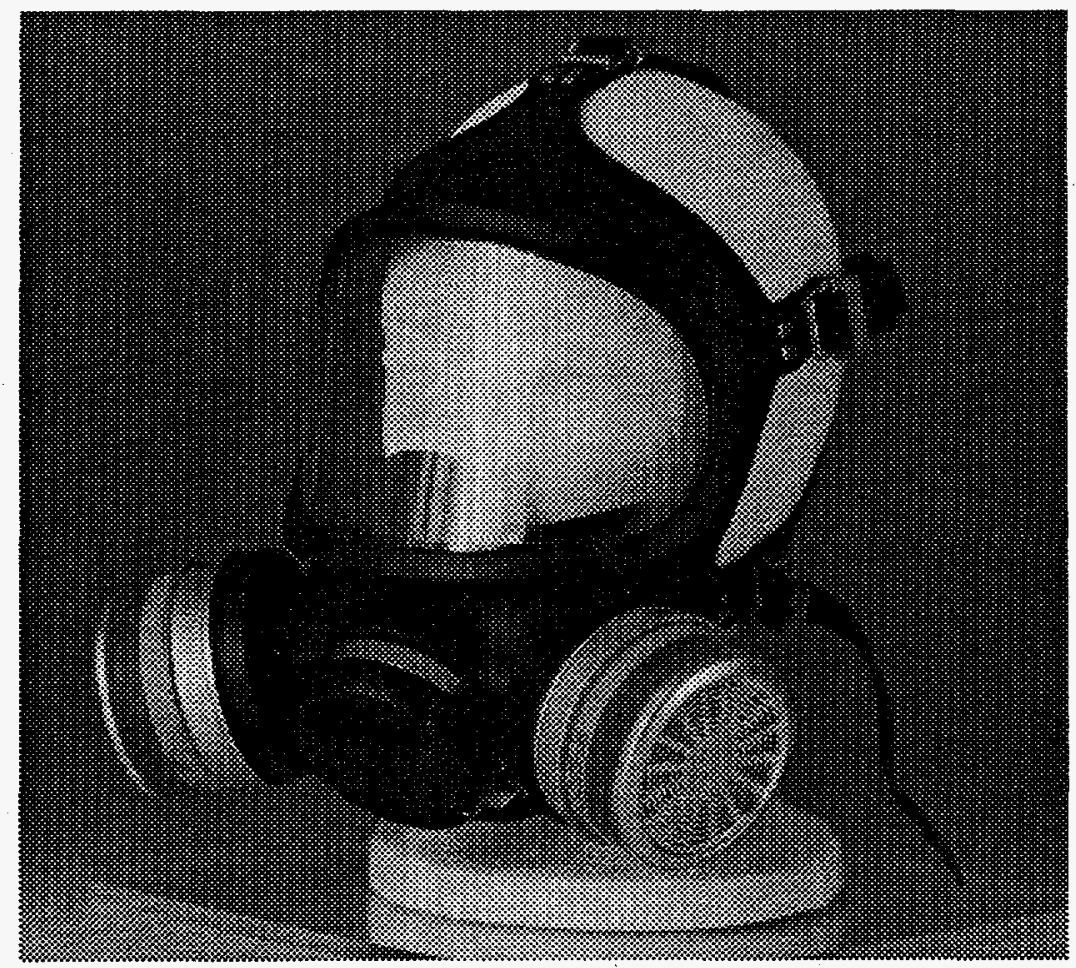

Figure 7. MSA Ultra-Twin

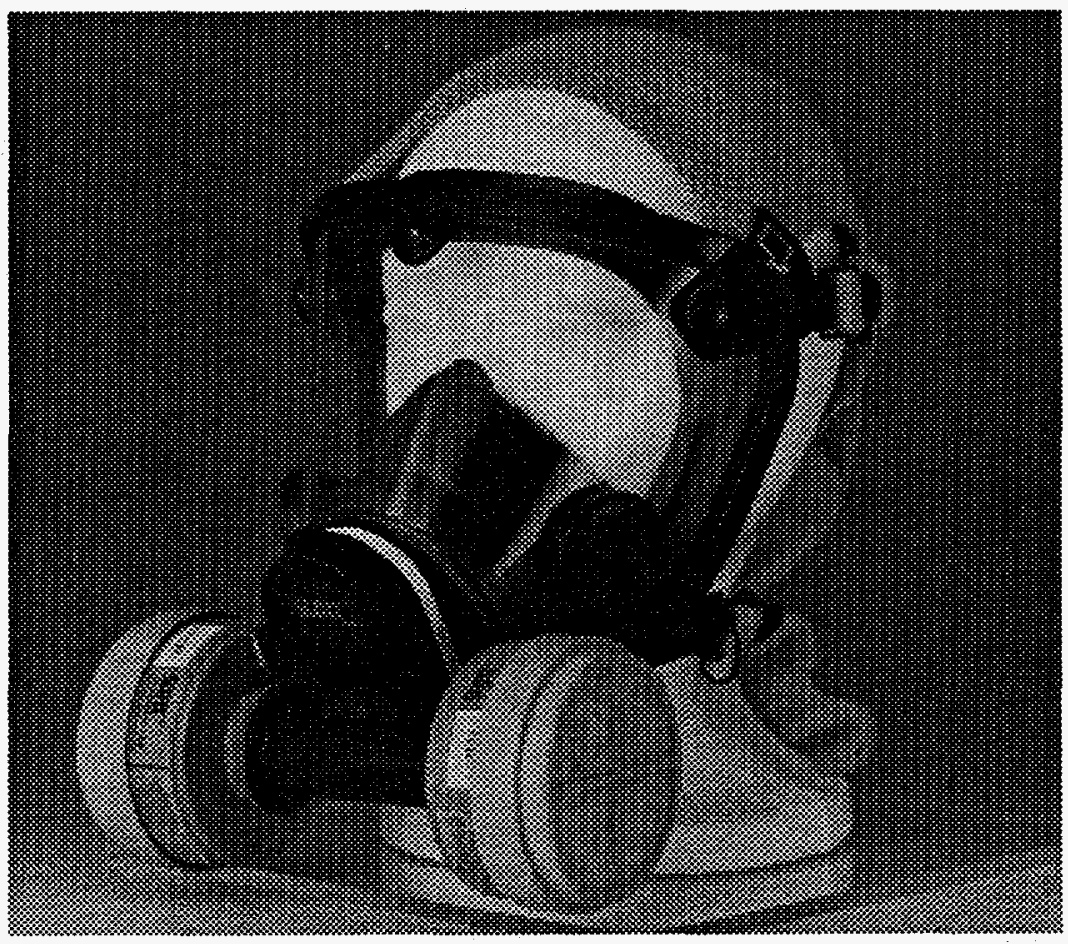

Figure 8. Scott O Vista Model 65 


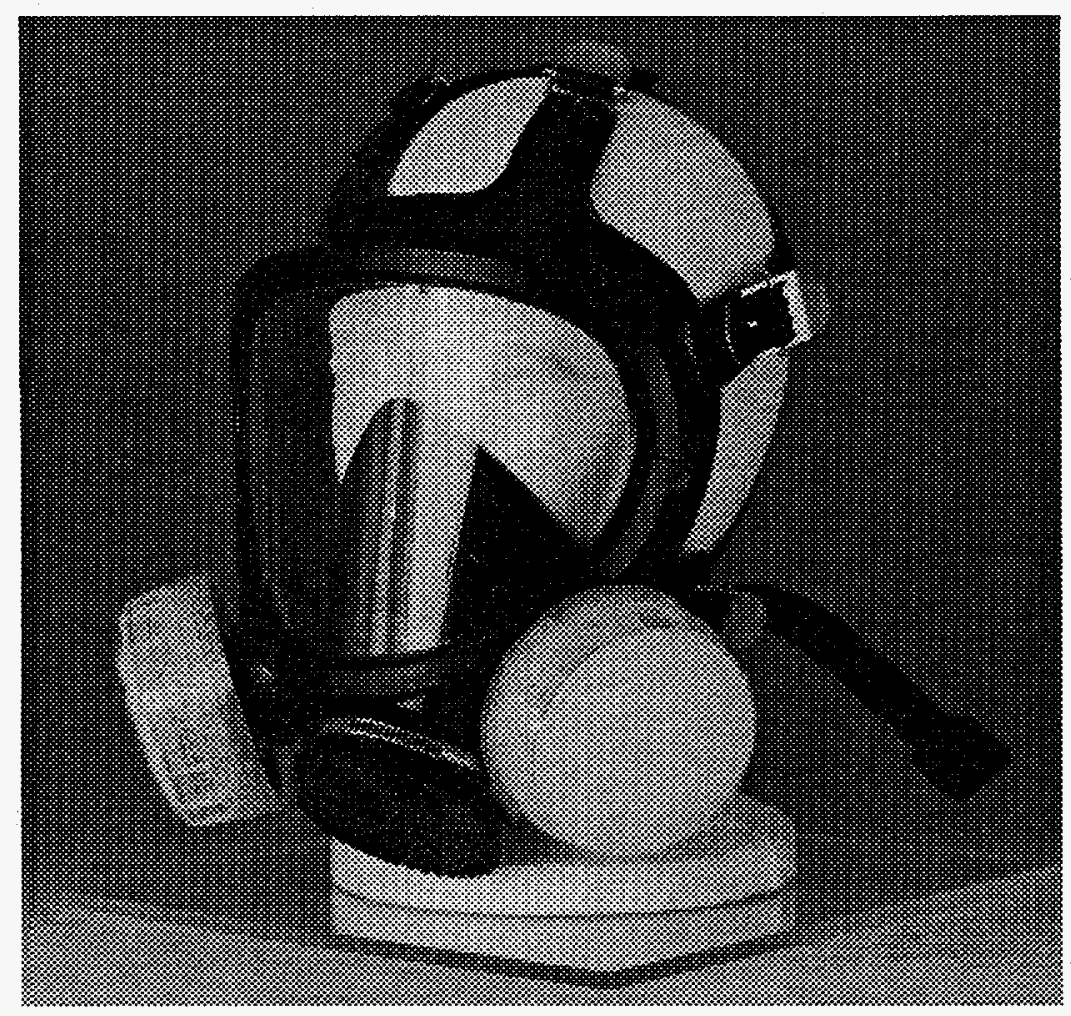

Figure 9. 3M Easi-Air

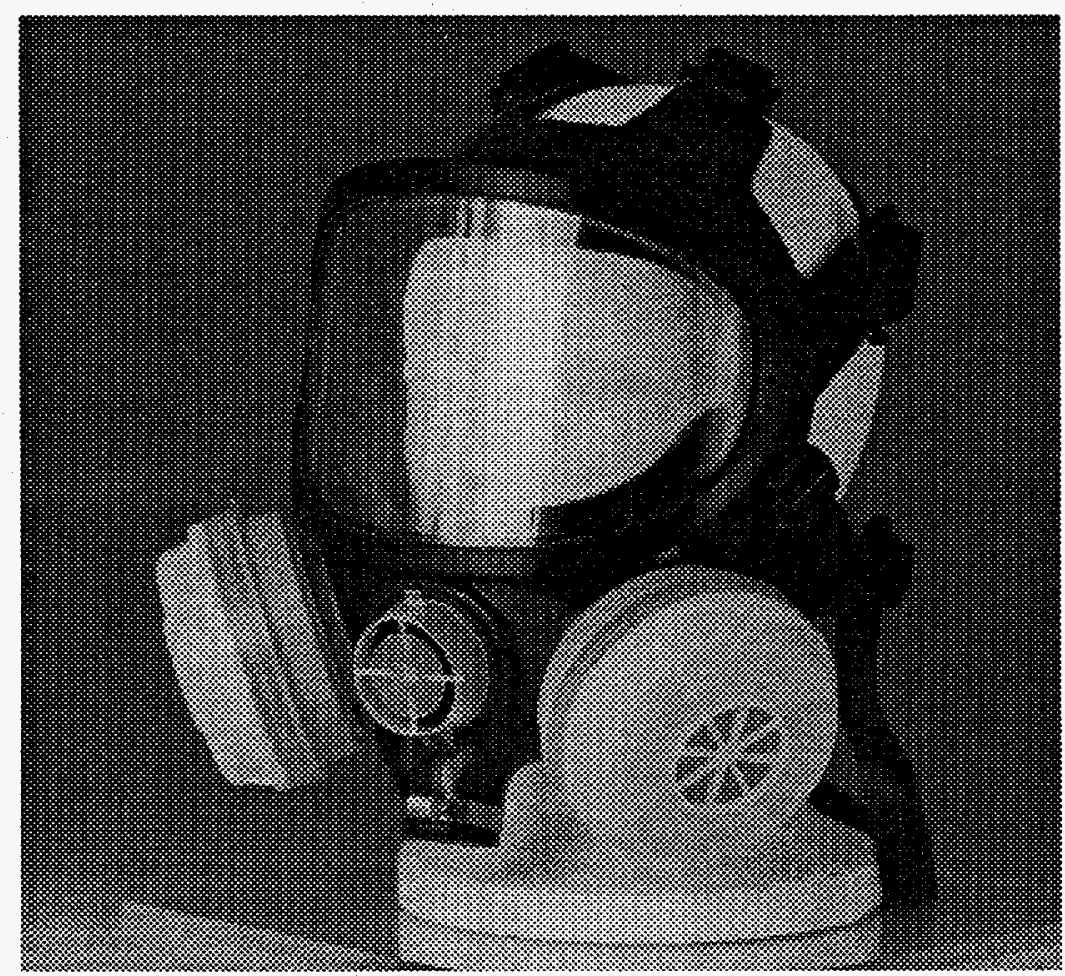

Figure 10. Wilson Model W6500 


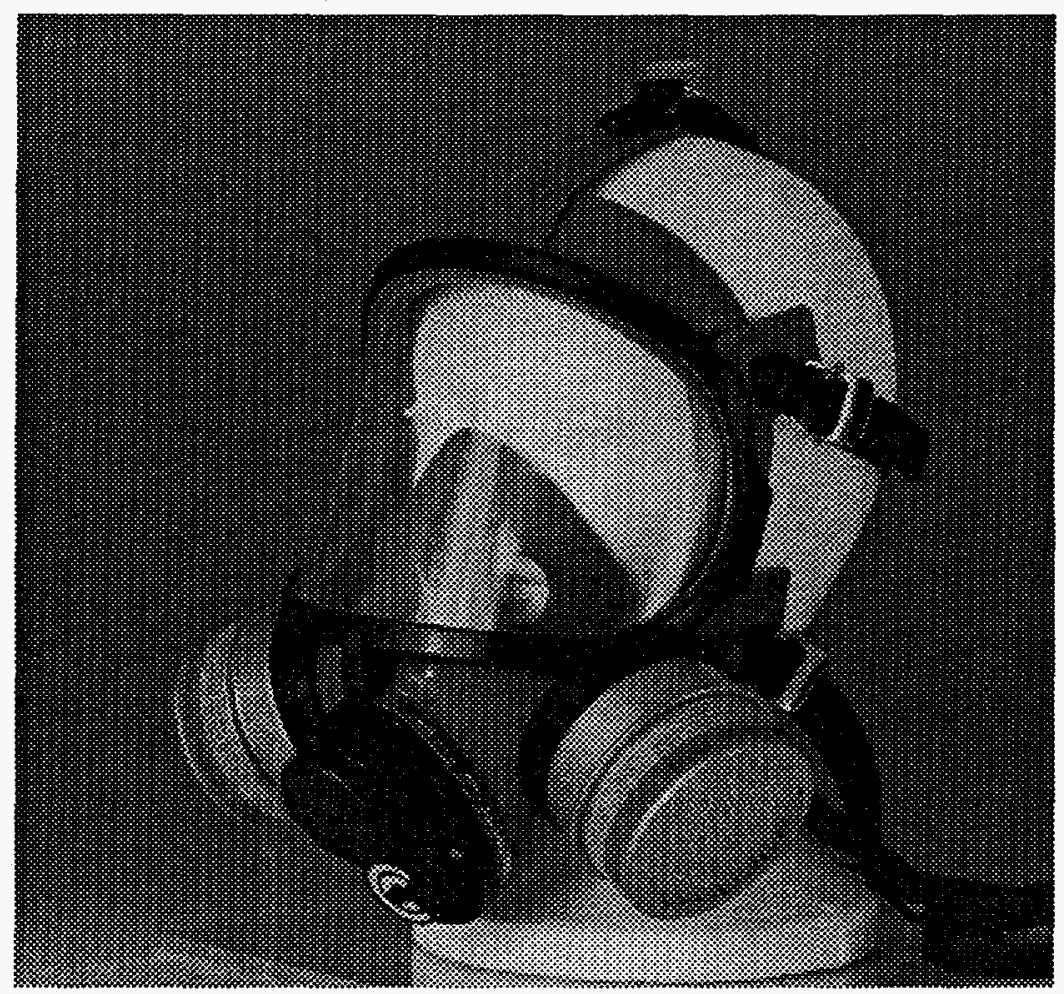

Figure 11. Cabot Omni Star

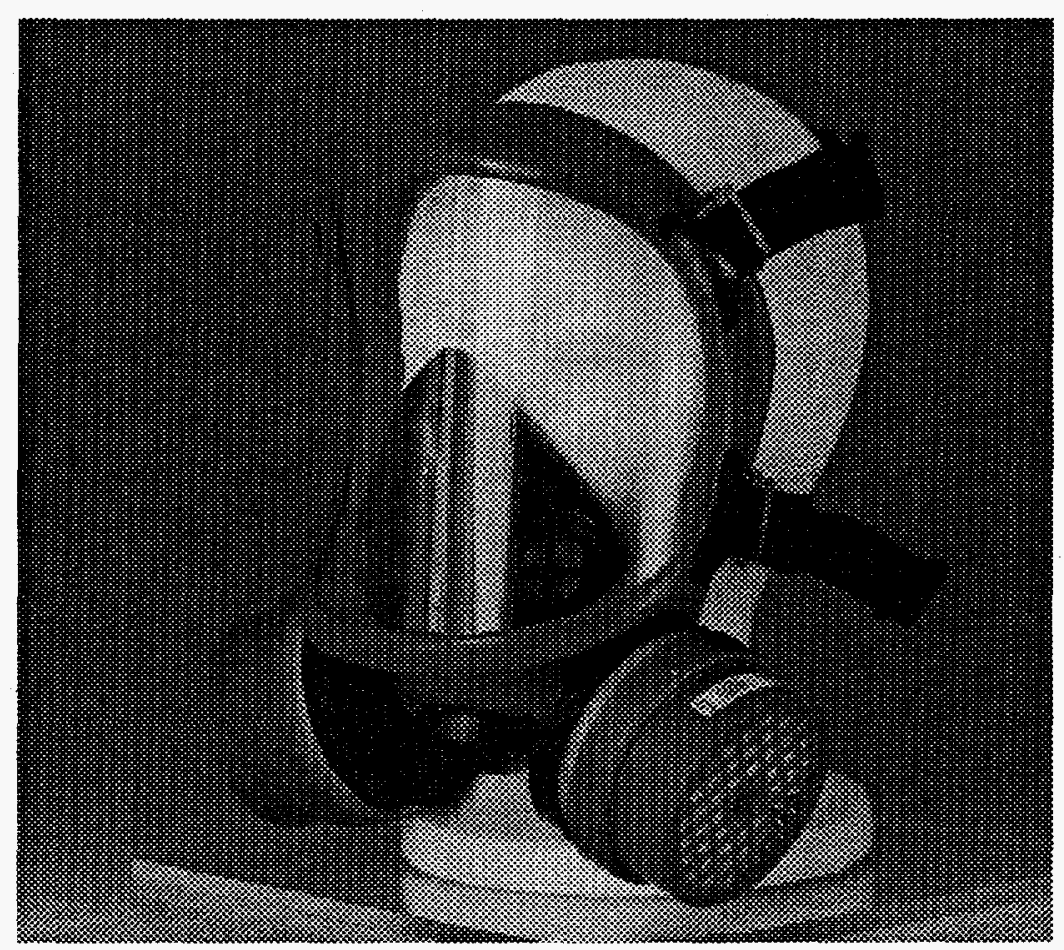

Figure 12. Pro-Tech Respirator 


\section{Project Elements}

The Respiratory Protection Program for this study contained many elements developed over the three-year evaluation program. The initial program included elements on:

- Field evaluation of the prototype "smart" air-purifying full-face respirator

- The physical ability of fire fighters to use a full-face air-purifying respirator during wildland fire fighting activities

- Development of a storage and carry pack for use by Helitack personnel

- Design of a helmet shroud that could be worn with or without the full-face respirator

- Medical surveillance and qualification

- Training of respirator users on use, care and cleaning of the "smart" respirator

- Fit testing

- Review of smoke and carbon monoxide exposure limits.

As the evaluation program developed, other elements were added to the respirator program. These additions included:

- Field evaluation of commercially available air-purifying respirators and various air-purifying cartridges

- Expanded training of respirator users on use, care and cleaning for the commercial respirators evaluated

- The fire stations ability to function independently and gather information on the respirator being evaluated

- Use of carbon monoxide data collection software and instruments,

- Understanding carbon monoxide exposure limits and physical effects of carbon monoxide exposure

- Stress associated with respirator usage. 


\section{Performance Goals}

Lawrence Livermore National Laboratory, Special Project Division goals for this project were to:

- Provide a technical basis, direction and advice to $\mathrm{CDF}$ in the development and evaluation of appropriate respirators for protection of wildland fire fighters from the short-term acute effects of wildland fire smoke.

- Interact with commercial respirator manufacturers to interest them in this problem and obtain equipment for evaluation to reduce project costs.

- Provide technical assistance and training to project participants as per 29 CFR 1910.134, ${ }^{2}$ ANSI Z88.2 - 1980, ${ }^{3}$ and TITLE 8 CCR $5155^{4}$ including, but not limited to: selection of respirators, explanation of personal exposure limits (PELs) and protection factors, donning and doffing procedures, and limitations of issued respirators.

- Conduct qualitative fit testing of all project participants.

- Provide training to approximately $10 \mathrm{CDF}$ fire suppression personnel in the use, maintenance and data transfer of carbon monoxide monitoring and data logging instruments.

- Evaluate prototype and commercially available respirators for their acceptability to be fielded as determined by CDF wildland fire fighters in controlled wildland fire responses.

- Compile a final report summarizing the findings of this project with recommendations to $\mathrm{CDF}$ on appropriate wildland fire fighter 
respiratory protection needs and performance requirements, as well as additional recommendations on specific items necessary for providing optimum wildland respiratory protection.

California Department of Forestry and Fire Protection was responsible for the coordination of the program and to:

- Provide approximately 50 wildland fire suppression personnel and partial funding for "smart" respirators for field evaluation.

- Coordinate the preparation for and the conducting of the respirator field evaluation.

- Coordinate the field evaluation process and collect respirator evaluation information and carbon monoxide data for analysis by LLNL.

- Assure that appropriate CAL/OSHA safety orders pertaining to respiratory protection were complied with through proper education and controls during the field evaluation period.

- Provide and collect participant consent forms for employees involved in the respirator evaluation study.

The CDF Medical Services Group conducted medical examinations on all fire fighters designated to wear respiratory protection equipment in this evaluation. CDF maintained records of all pulmonary function tests and medical records questionnaires. Each fire fighter received written approval that they were found medically fit to wear air-purifying respirators. Only those persons authorized to wear respiratory protection equipment, and were medically approved, fitted and trained, were assigned respiratory protection equipment at the fire stations for wildland fire use. 


\section{Respirator Selection/ Fit Testing}

The use of air-purifying respiratory protection in the fire service is nothing new. Before self-contained breathing apparatus was mandated by law for structural fire fighting, the Universal Canister full-face respirator (UCFR) was widely used. This air-purifying respirator used a canister that contained a filter, various absorbents and catalytic material to remove combustion products (e.g., soot, vapors, carbon monoxide).

For a number of reasons, inadequate protection from this type of respirator in structural fire fighting environments resulted in several major disabilities and deaths. These incidents culminated in the banning of the UCFR for structural fire fighting by the Department of Labor, Occupational Safety and Health Administration (OSHA). One overwhelming and ongoing concern has resulted from these incidents however, and that is the potential fire service misuse of airpurifying respirators.

Current respirator designs that incorporated powered air-purifying respirator (PAPR) systems with air-purifying cartridges are not feasible at this time for application to wildland fire suppression activities because of excessive weight, bulk and maintenance requirements. Wildland fire fighters routinely fight fires in remote locations which would create a significant problem to recharge or replace the batteries required for PAPR operation.

There are many types of respirators available, with each designed to protect against a specific type of hazard. In general, air-purifying respirators clean the air as the wearer breathes. For this evaluation program we selected a specific type of respirator cartridge to remove wildland fire emissions from the breathing air of the wearer. The selection of the type of respirator and cartridge was based on experience gained by the LLNL Fire Department. We used a modified Scott full face Model 65, Scott-O-Vista respirator with an OV/AG cartridge and prefilter for evaluation in the initial two years of the program. The fire fighters at LLNL have used this respirator model and type of cartridge for wildland fire fighting with no 
complaints of odor or eye irritation for the last 13 years. The OV/AG prefilter cartridge consists of adsorbents that remove volatile acid gases and organic vapors, and a prefilter for particulate removal. The other choice of cartridge evaluated in the third year of our study was the high efficiency particulate air filter(HEPA) which removes 99.97 percent of particulates 0.3 micrometers or larger in size. HEPA filter cartridges have a more extensive quality assurance program because the filter element is routinely tested to an efficiency of 99.97 percent. The respirator wearer must understand that the HEPA cartridge will not remove vapors or gases if they are used in wildland fire fighting applications.

The safe and effective use of a respirator for protection against toxic airborne material requires that the respirator be properly fitted to the person wearing it. Poor fitting respirators leak and thus fail to provide the required protection. No one size of respirator is capable of fitting all people. Several sizes may have to be fit tested on the wearer before the best fit is established. A fire fighter can not be fitted with a face-sealing respirator if there is any facial hair present that can come between the skin and mask-sealing surface. A moderate stubble at the sealing surface is considered excessive facial hair. The use of eye glasses with a full-face respirator is limited to applications that permit the glasses' frames to be fit into an adapter inside the respirator This adapter is designed by the respirator manufacturer to allow eye glasses to be worn inside the respirator and not interfere with the sealing surface of the face piece.

Each fire fighter was fitted using a respirator equipped with HEPA filters. Because the fitting of the respirators was conducted in the field we chose to perform a qualitative fit test. We used irritant smoke (stannic chloride) as the test agent to fit each fire fighter with the correct size of respirator. After each fire fighter was fit with the proper size respirator and completed the respirator training, a respirator and cartridges were issued to the individual. In the first two years of the program we issued the "smart" respirators with OV/AG cartridges and prefilter to each fire fighter. After each use we collected the respirator, checked the carbon monoxide monitor, inspected the respirator for damage, cleaned and refitted it with new cartridges and prefilters for the next use. 
In the third year of the program each fire fighter was issued a personal respirator for use during the entire test period. The long-term issue of the respirator was part of the evaluation program to determine the fire fighters' ability to care, clean and use the respirator during their normal work schedule. At selected fire stations we asked the fire fighters to use the HEPA filter as a training cartridge and to use it on at least one fire response. This use of the HEPA filter provided performance data for comparison to the OV/AG with prefilter. Information collected from each participating fire fighter indicated that the HEPA cartridge filtered out the particulate but allowed the acid gases and organic irritants to pass through the filter. This was evident by their ability to smell the smoke and experience some eye irritation. After using the HEPA filter for one fire the fire fighters installed either a OV/AG with prefilter or a OV/AG HEPA combination cartridge on the respirator for further use.

\section{Training of Respirator Wearer}

An effective respirator program for full-face air-purifying respirators must implement strict control procedures as well as an effective and realistic training program that details the equipment's limitations and how it should be used. To ensure the proper and safe use of a respirator, the minimum training of each wildland fire fighter included the following elements:

- The respiratory hazard and the effect on the wearer if the respirator is not used properly

- Proper selection of a respirator

- The function, capabilities, and limitations of the selected respirator

- Method of donning the respirator and checking its fit and operations

- Proper wearing of the respirator.

- Respirator maintenance, inspection, and storage

- Respirator Fit

- Facial hair, contact lens, and eye and face protection

- How one storage bag attaches to the web gear, use, and care

- Signs and effects of $\mathrm{CO}$ exposure and corrective actions 
- Cartridge types, when to change the cartridges

- Communications, hand signs, use of respirator with radio's.

\section{Respirator Field Use}

Care must be exercised in the use, cleaning, and maintenance of respirators. This section describes the controls which assured that each respirator utilized in this evaluation would function up to its design specifications.

1. Initial inspection - Immediately before using the respirator, the fire fighter shall remove it from its storage bag and:

a. Inspect it to determine if it is intact and complete.

b. Don the mask and perform both the positive and negative pressure fit-tests to ascertain that the valves and face seal are working properly.

c. Repair, clean, or replace respirators that are damaged, dirty, or fail to fit properly.

2. Cleaning and Sanitation - Cleaning and sanitizing shall be per formed in the following manner:

a. Wipe down all silicone and rubber surfaces of the respirator with alcohol, or other approved wipes, on a daily basis. Pay special attention to wipe the face-sealing area and clean the respirator several times a day in dusty environments or;

b. Remove the cartridges and wash the entire respirator with soap and warm water in a clean area at least once a week. Allow it to dry at room temperature for one to two days, or at elevated temperatures for a shorter time period.

3. Storage - When not in use, respirators should be stored to protect them from dust, sunlight, extremes of temperature, excessive moisture or damaging chemicals. Respirators should be stored in the storage bag provided by the manufacturer or an equivalent (e.g., Nomex storage bag that attaches to web gear). 
4. Replacement of Cartridges - If cartridges become saturated (indicated by odor detection) or filter media clogged (indicated by increased breathing resistance) with combustion contaminants the cartridge should be replaced.

\section{Smoke Exposure}

Wildland smoke contains many toxic components. We refer the reader to K.L. Foote, Determination of Toxic Material Penetrations for Wildland Respirator Filters, for a more complete understanding of the toxic material fire fighters are exposed to during their wildland fire fighting activities.

In Foote's report he describes a reliable test method to simulate wildland fire conditions and produce a consistent and reproducible smoke exposure for time periods of 20 minutes. Using this smoke exposure test method, Foote was able to demonstrate that the activated carbon cartridge and prefilter effectively collected $100 \%$ of the formaldehyde gas for up to 60 minutes, however, it only collected 85 percent of the challenge particulate. The bandanna used by many wildland fire fighters as expected performed poorly in collecting smoke particulate and removed no toxic gases. In a smoke exposure test of a HEPA filter and activated carbon combination cartridge, no formaldehyde, acrolein, or detectable mass increase was detected downstream of the test filter for 20 minutes of exposure.

Foote also suggested that the combination HEPA filter and activated carbon cartridge warrants further testing based on the excellent preliminary test results. This combination cartridge could prove to be a superior wildland fire fighter airpurifying element.

A major toxic component of wildland fire fighting exposure is carbon monoxide. Carbon monoxide ( $\mathrm{CO}$ ) is a colorless odorless toxic gas that is a component of smoke. Current limits set by CAL/OSHA have a time weighted average (TWA) 
of $25 \mathrm{ppm}$ for an eight-hour work day exposure limit with a $200 \mathrm{ppm}$ ceiling exposure limit.4 The effects of $\mathrm{CO}$ on the human body varies with the physical condition, the breathing rate and the pulmonary volume of the individual. ${ }^{5}$ At a concentration of $200 \mathrm{ppm}$ an individual will start experiencing mild headaches after two to three hours exposure. At a $400 \mathrm{ppm}$ exposure the individual can experience major headaches and nausea after one to two hours of exposure. Carbon monoxide is also recognized to cause a person's reasoning process to diminish which results in the possibility of increased numbers of incorrect decisions. With an exposure concentration of $800 \mathrm{ppm}$ and higher the effects of $\mathrm{CO}$ exposure become very serious. Death may occur after an exposure of $1600 \mathrm{ppm}$ in as little time as two hours.

Actual $\mathrm{CO}$ exposure data collected during the evaluation test periods was very limited because of the low number of fire incidents. $\mathrm{CO}$ data from the first two summers was collected and analyzed on the fire scene or in the station by LLNL technical personnel. Each CO monitor and data logger, National Draeger Model 190 ( Fig. 13), was calibrated at the beginning of each day before they were issued to the fire fighters. At the end of the day data was downloaded to a portable computer (Fig. 14) and analyzed using the National Draeger Enhanced Graphs Software (version 2.0). Confidence levels for this data is very good. If an instrument was found defective it was repaired by LLNL personnel and put back in service after calibration. Carbon monoxide data collected during the third summer at three fire stations by CDF personnel was incomplete. Even though training was provided at each station to the various participants this new task competed with other daily activities. After our initial visit station staff paid little attention to daily calibration of the $\mathrm{CO}$ monitor and data logger. Difficulties were also experienced with use of the instruments and computer data acquisition system which were not brought to our attention. The data from Howard Forest Fire Station, however, was different because it did show a high degree of confidence and it was useful in the study. 


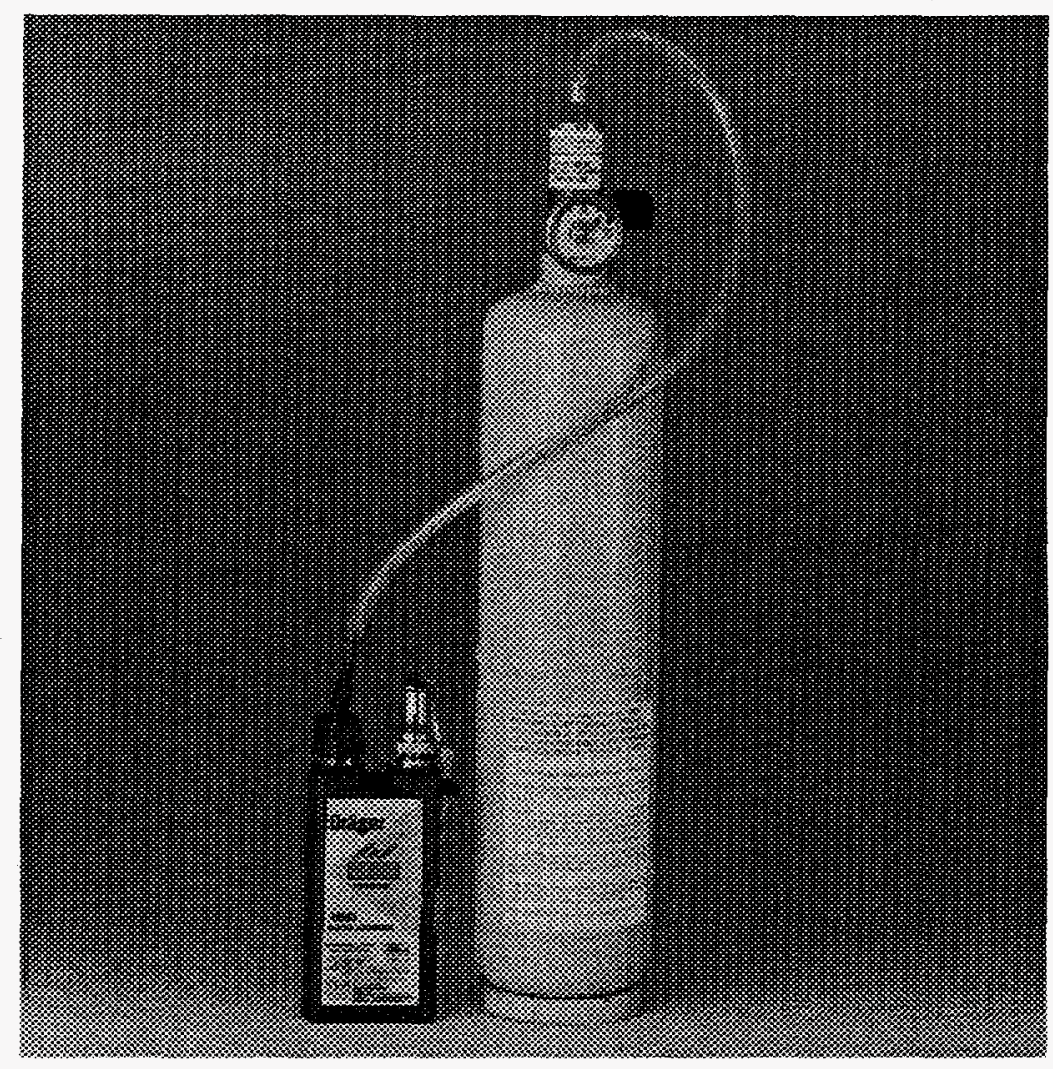

Figure 13. CO Data Logger

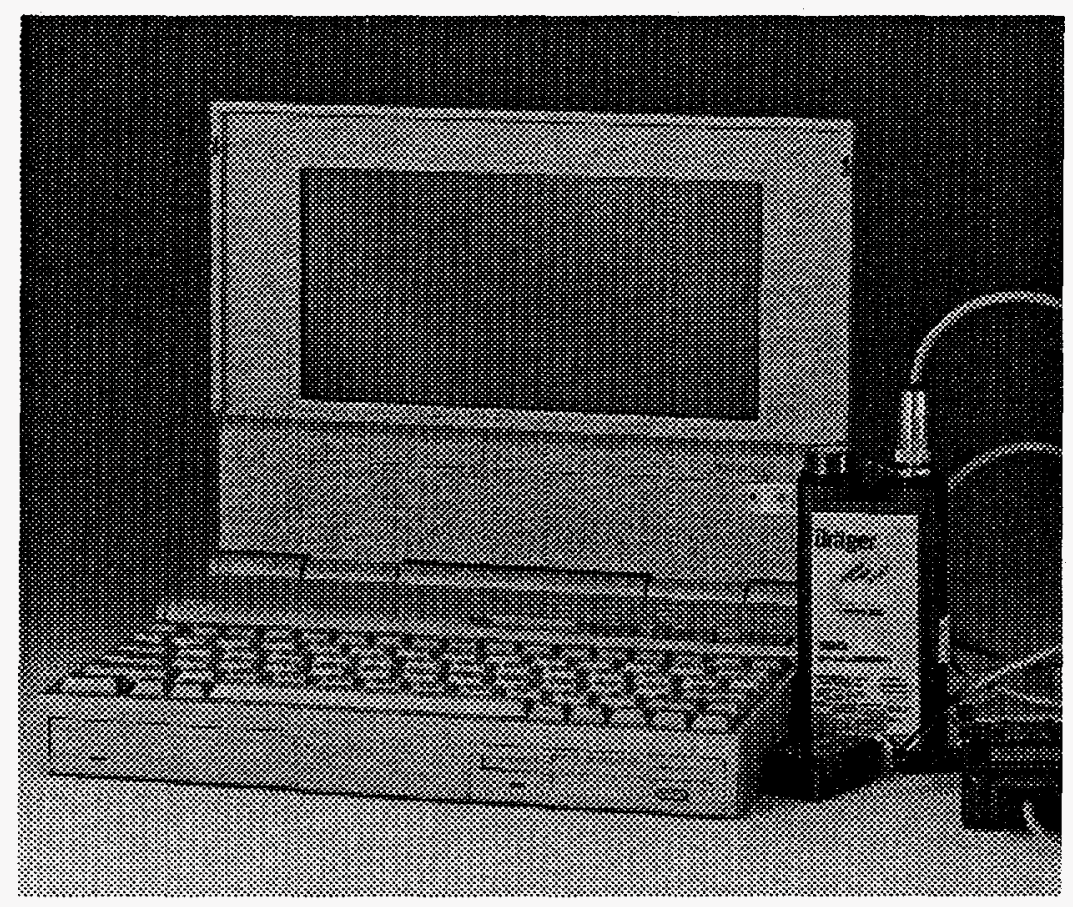

Figure 14. Computer System for recording data 
Table 2 is a summary of the $\mathrm{CO}$ data acquired over the three summers of the evaluation program. The table shows the maximum $\mathrm{CO}$ concentration, average $\mathrm{CO}$ exposure for the incident exposure period, and the time of exposure for each incident. The highest peak exposure recorded was $703 \mathrm{ppm}$ for the 60 -second sample time with an average exposure of $42 \mathrm{ppm}$ for a 55-minute exposure.

In general the table shows that the majority of the exposure to fire fighters was below the $25 \mathrm{ppm}$ TWA limit, with a few exposures exceeding the $25 \mathrm{ppm}$ limit but for a much shorter time period. 
Table 2

CO Exposure Data 1991, 1992, 1993

\begin{tabular}{|c|c|c|c|}
\hline $\begin{array}{l}\text { DATA FILE } \\
\text { NUMBER }\end{array}$ & PEAK CO CONC & $\begin{array}{l}\text { AVERAGE CO } \\
\text { EXPOSURE }\end{array}$ & $\begin{array}{c}\text { DURATION OF } \\
\text { EXPOSURE }\end{array}$ \\
\hline & PPM & PPM & MINUTES \\
\hline 1 & 74 & 4 & $271 \mathrm{MIN}$ \\
\hline 2 & 50 & 7 & $75 \mathrm{MIN}$ \\
\hline 3 & 119 & 10 & $140 \mathrm{MIN}$ \\
\hline 4 & 53 & 6 & $629 \mathrm{MIN}$ \\
\hline 5 & 46 & 18 & $18 \mathrm{MIN}$ \\
\hline 6 & 74 & 9 & $115 \mathrm{MIN}$ \\
\hline 7 & 45 & 13 & 22 MIN \\
\hline 8 & 17 & SINGLE PEAK & \\
\hline 9 & 68 & 11 & $194 \mathrm{MIN}$ \\
\hline 10 & 169 & 22 & $45 \mathrm{MIN}$ \\
\hline 11 & 79 & 7 & $234 \mathrm{MIN}$ \\
\hline 12 & 65 & $\overline{14}$ & $267 \mathrm{MIN}$ \\
\hline 13 & 39 & 10 & $95 \mathrm{MIN}$ \\
\hline 14 & 72 & 13 & $39 \mathrm{MIN}$ \\
\hline 15 & 46 & 18 & $265 \mathrm{MIN}$ \\
\hline 16 & 129 & 14 & $200 \mathrm{MIN}$ \\
\hline 17 & 18 & SINGLE PEAK & \\
\hline 18 & 28 & SINGLE PEAK & \\
\hline 19 & 10 & SINGLE PEAK & \\
\hline 20 & 21 & SINGLE PEAK & \\
\hline 21 & 8 & SINGLE PEAK & \\
\hline 22 & 74 & 10 & $235 \mathrm{MIN}$ \\
\hline 23 & $\overline{43}$ & 19 & $350 \mathrm{MIN}$ \\
\hline 24 & 27 & SINGLE PEAK & \\
\hline 25 & 28 & SINGLE PEAK & \\
\hline 26 & 21 & SINGLE PEAK & \\
\hline 27 & 66 & 6 & $314 \mathrm{MIN}$ \\
\hline 28 & 101 & 15 & $50 \mathrm{MIN}$ \\
\hline 29 & 65 & 9 & $66 \mathrm{MIN}$ \\
\hline 30 & 65 & 14 & $285 \mathrm{MIN}$ \\
\hline 31 & 26 & SINGLE PEAK & \\
\hline 32 & 90 & 19 & 365 MIN \\
\hline 33 & 93 & 12 & $210 \mathrm{MIN}$ \\
\hline 34 & 33 & SINGLE PEAK & \\
\hline 35 & 160 & 28 & $82 \mathrm{MIN}$ \\
\hline 36 & 51 & 10 & $115 \mathrm{MIN}$ \\
\hline 37 & 57 & 10 & $59 \mathrm{MIN}$ \\
\hline
\end{tabular}


Table 2

CO Exposure Data 1991, 1992, 1993

\begin{tabular}{|c|c|c|c|}
\hline $\begin{array}{l}\text { DATA FILE } \\
\text { NUMBER }\end{array}$ & PEAK CO CONC & $\begin{array}{l}\text { AVERAGE CO } \\
\text { EXPOSURE }\end{array}$ & $\begin{array}{l}\text { DURATION OF } \\
\text { EXPOSURE }\end{array}$ \\
\hline & PPM & PPM & MINUTES \\
\hline 38 & 108 & 11 & 106 \\
\hline 39 & 91 & 21 & $23 \mathrm{MIN}$ \\
\hline 40 & 53 & 4 & 365 \\
\hline 41 & 8 & SINGLE PEAK & \\
\hline 42 & 36 & SINGLE PEAK & \\
\hline 43 & 56 & 3 & 225 MIN \\
\hline 44 & 76 & 4 & $153 \mathrm{MIN}$ \\
\hline 45 & 29 & SINGLE PEAK & \\
\hline 46 & 104 & 19 & $58 \mathrm{MIN}$ \\
\hline 47 & 229 & 96 & $6 \mathrm{MIN}$ \\
\hline 48 & 8 & SINGLE PEAK & \\
\hline 49 & 178 & 6 & $474 \mathrm{MIN}$ \\
\hline 50 & 13 & SINGLE PEAK & \\
\hline 51 & 16 & SINGLE PEAK & \\
\hline 52 & 16 & SINGLE PEAK & \\
\hline 53 & 9 & SINGLE PEAK & \\
\hline 54 & 92 & 9 & $1000 \mathrm{MIN}$ \\
\hline 55 & 167 & 8 & $224 \mathrm{MIN}$ \\
\hline 56 & 4 & SINGLE PEAK & \\
\hline 57 & 24 & SINGLE PEAK & \\
\hline 58 & 119 & 6 & $400 \mathrm{MIN}$ \\
\hline 59 & 201 & “26,58” & "15,25 MIN" \\
\hline 60 & 64 & 12 & $37 \mathrm{MIN}$ \\
\hline 61 & 107 & 19 & $50 \mathrm{MIN}$ \\
\hline 62 & 398 & 18 & $40 \mathrm{MIN}$ \\
\hline 63 & 703 & 42 & $55 \mathrm{MIN}$ \\
\hline 64 & 64 & 5 & $155 \mathrm{MIN}$ \\
\hline 65 & 240 & 32 & $130 \mathrm{MIN}$ \\
\hline 66 & 40 & SINGLE PEAK & \\
\hline 67 & 55 & SINGLE PEAK & \\
\hline 68 & 99 & 5 & $490 \mathrm{MIN}$ \\
\hline 69 & 82 & 9 & $133 \mathrm{MIN}$ \\
\hline 70 & 92 & 30 & $30 \mathrm{MIN}$ \\
\hline 71 & 187 & SINGLE PEAK & \\
\hline 72 & 222 & 30 & $49 \mathrm{MIN}$ \\
\hline 73 & 213 & 15 & $264 \mathrm{MIN}$ \\
\hline 74 & 69 & 14 & $32 \mathrm{MIN}$ \\
\hline 75 & 52 & 14 & $35 \mathrm{MIN}$ \\
\hline 76 & 92 & 5 & $125 \mathrm{MIN}$ \\
\hline 77 & 4 & SINGLE PEAK & \\
\hline 78 & 20 & SINGLE PEAK & \\
\hline
\end{tabular}


Table 2

CO Exposure Data 1991, 1992, 1993

\begin{tabular}{|c|c|c|c|}
\hline $\begin{array}{l}\text { DATA FILE } \\
\text { NUMBER }\end{array}$ & PEAK CO CONC & $\begin{array}{c}\text { AVERAGE CO } \\
\text { EXPOSURE }\end{array}$ & $\begin{array}{c}\text { DURATION OF } \\
\text { EXPOSURE }\end{array}$ \\
\hline & PPM & PPM & MINUTES \\
\hline 79 & 23 & SINGLE PEAK & \\
\hline 80 & 14 & SINGLE PEAK & \\
\hline 81 & 16 & SINGLE PEAK & \\
\hline 82 & 21 & SINGLE PEAK & \\
\hline 83 & 105 & 15 & $204 \mathrm{MIN}$ \\
\hline 84 & 13 & SINGLE PEAK & \\
\hline 85 & 11 & SINGLE PEAK & \\
\hline 86 & 18 & SINGLE PEAK & \\
\hline 87 & 10 & SINGLE PEAK & \\
\hline 88 & 149 & 35 & $225 \mathrm{MIN}$ \\
\hline 89 & 10 & SINGLE PEAK & \\
\hline 90 & 20 & SINGLE PEAK & \\
\hline 91 & 96 & 5 & $113 \mathrm{MIN}$ \\
\hline 92 & 5 & SINGLE PEAK & \\
\hline 93 & 157 & 4 & $200 \mathrm{MIN}$ \\
\hline 94 & 12 & SINGLE PEAK & \\
\hline 95 & 25 & SINGLE PEAK & \\
\hline 96 & 37 & 6 & 720 M IN \\
\hline & 97 & 89 & $750 \mathrm{MIN}$ \\
\hline 98 & 8 & SINGLE PEAK & \\
\hline 99 & 14 & SINGLE PEAK & \\
\hline 100 & 69 & 34 & 600 MIN \\
\hline 101 & 9 & SINGLE PEAK & \\
\hline 102 & 12 & SINGLE PEAK & \\
\hline 103 & 11 & SINGLE PEAK & \\
\hline 104 & 51 & 18 & $500 \mathrm{MIN}$ \\
\hline 105 & 93 & 17 & 584 MIN \\
\hline 106 & 28 & 10 & $734 \mathrm{MIN}$ \\
\hline 107 & 31 & 16 & $13 \mathrm{MIN}$ \\
\hline 108 & 82 & 4 & 252 MIN \\
\hline 109 & 19 & SINGLE PEAK & \\
\hline 110 & 11 & SINGLE PEAK & \\
\hline 111 & 33 & 5 & $252 \mathrm{MIN}$ \\
\hline 112 & 44 & 5 & $100 \mathrm{MIN}$ \\
\hline 113 & 14 & SINGLE PEAK & \\
\hline 114 & 39 & 5 & $614 \mathrm{MIN}$ \\
\hline 115 & 65 & 5 & $236 \mathrm{MIN}$ \\
\hline 116 & 105 & 15 & $206 \mathrm{MIN}$ \\
\hline 117 & 10 & SINGLE PEAK & \\
\hline 118 & 14 & SINGLE PEAK & \\
\hline 119 & 32 & 5 & $614 \mathrm{MIN}$ \\
\hline
\end{tabular}


Table 2

CO Exposure Data 1991, 1992, 1993

\begin{tabular}{|c|c|c|c|}
\hline $\begin{array}{c}\text { FILE DATA } \\
\text { NUMBER }\end{array}$ & PEAK CO CONC & $\begin{array}{c}\text { AVERAGE CO } \\
\text { EXPOSURE }\end{array}$ & $\begin{array}{c}\text { DURATION OF } \\
\text { EXPOSURE }\end{array}$ \\
\hline 120 & PPM & PPM & MINUTES \\
\hline 121 & 15 & SINGLE PEAK & \\
\hline 122 & 56 & 5 & 300 MIN \\
\hline
\end{tabular}

Wildland fire fighters wearing air-purifying respirators have to be aware of their exposure to $\mathrm{CO}$. The use of an air-purifying respirator will allow a wildland fire fighter to stay in a smoke environment for a longer period of time than if they were not wearing a respirator. The longer exposure to the filtered smoke atmosphere will increase the potential for exposure to $\mathrm{CO}$. This would not normally happen because one breath of the heavy particle laden smoke would drive the fire fighter out of the unacceptable environment and into clean air. Because of this ability to stay in the smoke longer and still perform their duties each fire fighter should have the ability to monitor for $\mathrm{CO}$ while fighting a wildland fire in an air-purifying respirator.

A high $\mathrm{CO}$ exposure to a fire fighter was recorded during a control burn. This fire fighter was following an engine laying a wet line in front of a fire fighter setting the back fire in a grass land fire. The high exposure was a combination of $\mathrm{CO}$ from the grass fire and the engine exhaust coming from the fire engine. After the exposure was noted the fire fighter laying the wet line moved to the front of the engine and minimized his exposure to the exhaust from the engine. This change in work practice reduced the CO exposure to an acceptable level.

While conducting a training exercise with a Fire Engine Company at Vina Helitack we also noted a high exposure to $\mathrm{CO}$ from the truck engine and from the auxiliary pump engine. These examples indicate the importance of recognizing fire fighting vehicles as sources of $\mathrm{CO}$ exposure which must be evaluated. Levels of $\mathrm{CO}$ from these exhaust systems can reach dangerous concentrations very fast. 
Another high exposure was found inside of the cab of an older engine at the Perris Station. The engine had an exhaust leak and the $\mathrm{CO}$ concentration in the cab exceeded $200 \mathrm{ppm}$ while riding to a fire. This was a case of exposure to $\mathrm{CO}$ that was not caused by a fire. The use of a $\mathrm{CO}$ monitor in this case helped to reduce personal exposure to $\mathrm{CO}$ and identified a mechanical problem in the engine.

\section{Helmet, Shroud, and Storage pack}

During the first summer at CDF Vina, we developed a storage pack for the "smart" respirator that would allow the respirator to be attached to the front of the web gear currently being worn by the Helitack crew. This storage pack (Fig. 15) has a side pouch for a radio and an additional pouch for the $\mathrm{CO}$ monitor and data logger. There is also a small pouch that could be used for map storage or for the storage of extra cartridges. The front-mounted storage pack had some disadvantages for the drivers of the engine companies and for some female fire fighters. The pack with the respirator inside interfered with the steering wheel and had to be removed by the driver each time he got in the engine. Female fire fighters complained the addition of the pack over the breast area presented a vision problem resulting in their inability to see the ground immediately in front of their feet. Some fire fighters modified the storage pack to fit on the web gear under the left arm or on the back of the web gear. The design of a new storage pack should be such that it has a number of attachment options.

The shroud (Fig. 16) that was developed at Vina in the first year was made slightly larger to accommodate the different style of face pieces that were used in the last year of evaluations. The Velcro attachment strips were made longer to accommodate different head sizes and mask arrangement. The elastic chin strap on the helmet was replaced with a more rigid type with a quick disconnect buckle and adjustable strap to allow for use with the respirator. The headband in the helmet was replaced with a ratchet type adjustable headband. This feature is a necessity to allow for the quick adjustment required of the headband each time the respirator is put on or taken off. 


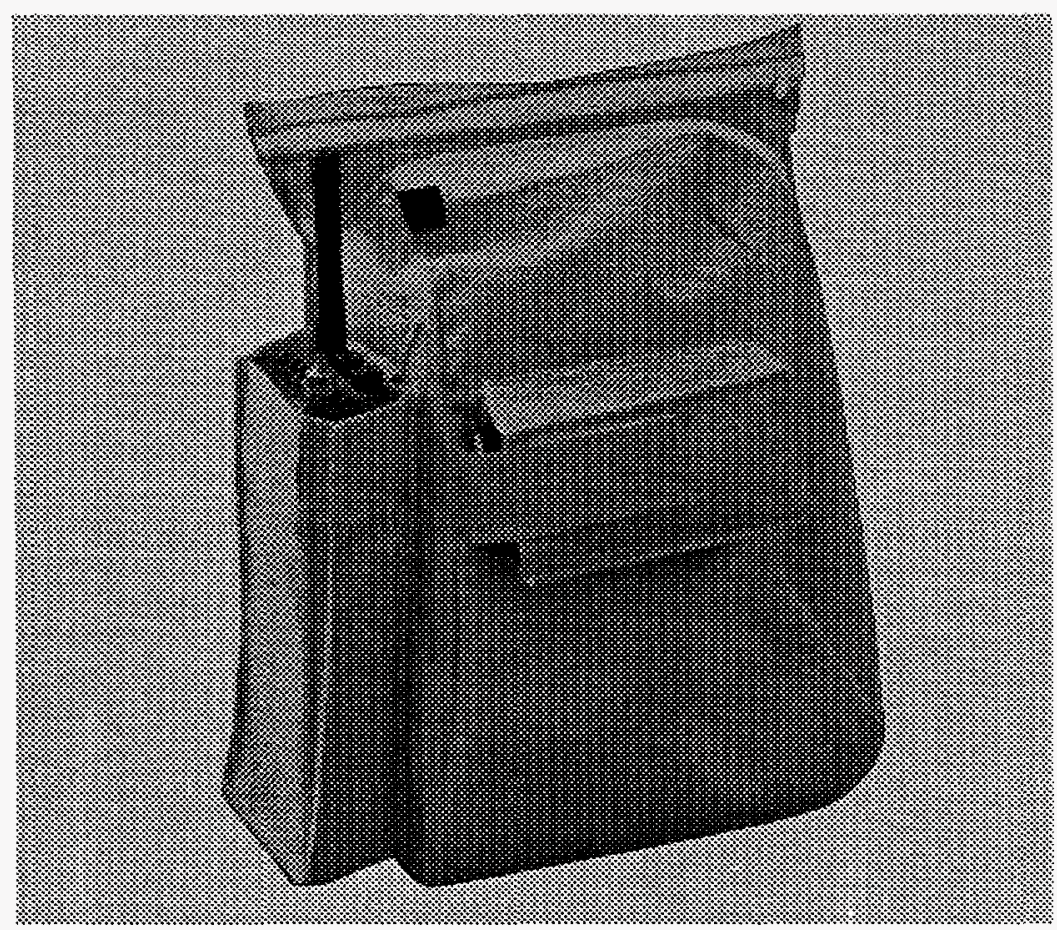

Figure 15. Storage pack

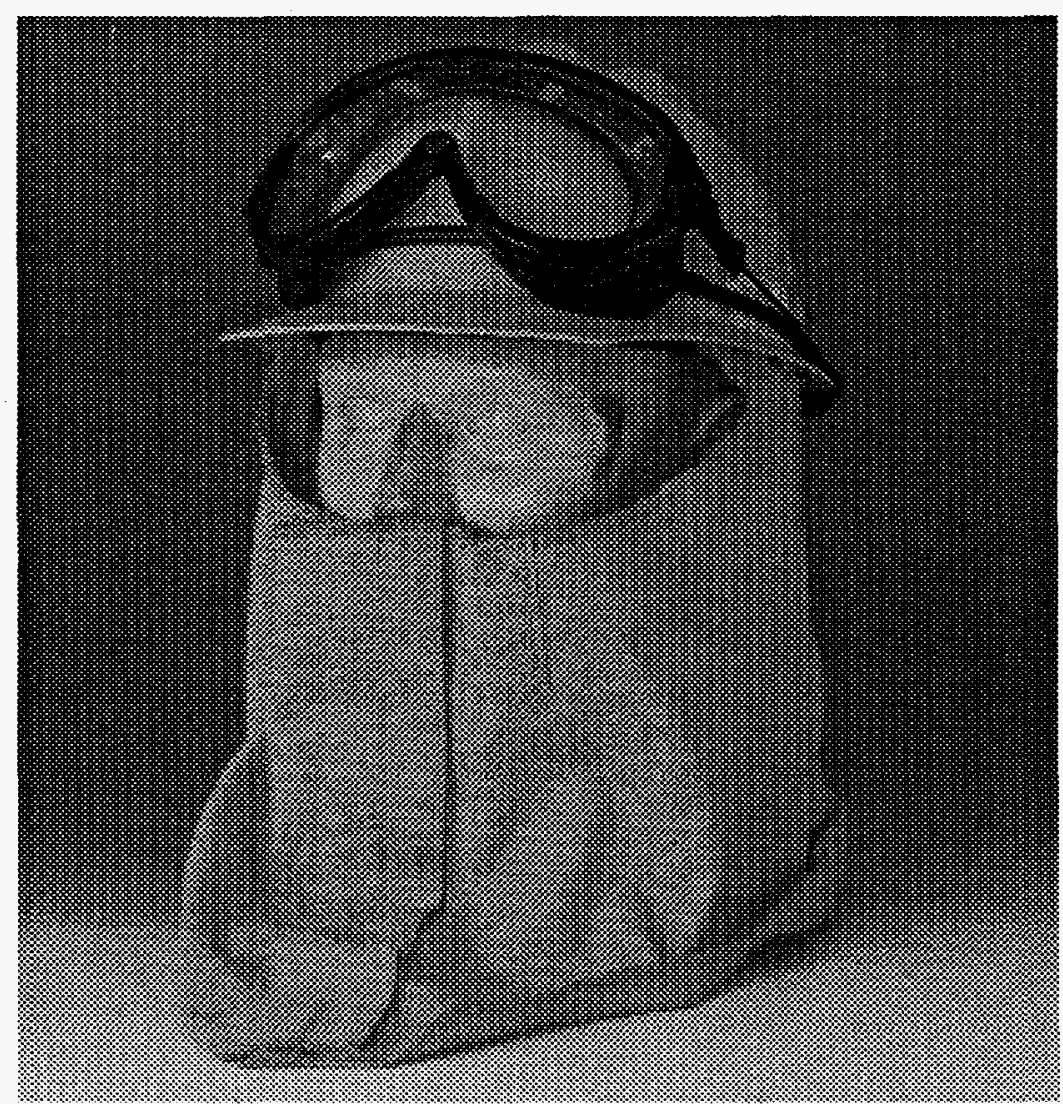

Figure 16. Modified Shroud 


\section{SUMMARY OF QUESTIONNAIRES}

At the end of each day or fire response each wildland fire fighter was asked to fill out a questionnaire. The senior person in charge of the crew was also asked to fill out a summary sheet on the fire incident and give a brief over view of the type of training or fire exposure received. The majority of the information collected in the first two years was reinforced by information also collected by LLNL personnel operating with the CDF crews. For the last year of the program we relied on the crew captain or senior person to obtain the data and file it for later data analysis. The questionnaire used for the first two years (Appendix II) asked basic questions on the use, fit, visibility, ability to work, etc. For the last year of the program we expanded the questionnaire (Appendix III) to be more specific on the use of the respirator. In addition, we attempted to grade the use of the respirator by asking the user to rank certain questions on a scale of 1 to 10 with 1 being the best and 10 being the worst. Because of the nature of the questions and the number of questionnaires they will not be included in this report. The original questionnaires will be kept on file at LLNL. The final questionnaire filled out by the fire fighters at the end of the third year provided a very good summary of the needs and likes and dislikes of wildland respirator use.

\section{Final Questionnaire}

At the end of the third year we conducted personal interviews with as many of the fire fighters involved in the program as possible. At the final interview all the respirators used in the study were available to each fire fighter for his evaluation during the interview. Because some fire fighters had been released for the year or were not available for the interview when we visited each station we did not achieve 100 percent participation. We did, however, obtain 54 percent participation of wildland respirator users in our personal interview process. The following is a summary of the answers to questions asked in the final interview of 32 fire fighters. Of the 32 questioned, 29 had a positive attitude toward the use of an air-purifying respirator. Three fire fighters stated that they felt it wasn't a useful tool and didn't like wearing an air-purifying respirator during wildland fire fighting operations. 
1. Describe the positive aspects of wearing a full-face air-purifyimg respirator while performing you job.

Most people commented on the improved ability to breath, less eye irritation, better visibility in smoke. They also felt that they could make better decisions when overrun by smoke. In addition, they felt they were able to make better judgment calls because smoke exposure did not take their breath away and force them to run for fresh air.

\section{Describe the negative aspects of wearing a full-face air-purifyimg respirator while performing your job.}

The restriction of breathing reduces the ability to perform the job at the current high work rate expected by the fire fighters. The wildland respirator is difficult to wear during arduous physical activity such as a progressive hose lay if required to run up and down hills. Communication is very difficult if not impossible while wearing the respirator.

3. Now that you have worn a full-face air-purifyimg respirator for a period of time, describe the ideal respirator that you would like to wear. Use the available respirator samples as a guide.

a) Optional soft net style head strap (Scott) or multistrap harness (at least 5 points)

b) Soft silicone style face seal (Survivair, 3-M, Draeger, Pro-Tech)

c) Low resistance to inhalation, exhalation

d) Removable filter manifold (Scott)

e) Better communications ability (MSA 2000)

f) Low distortion lens (Pro-Tech)

g) Different size nose cups

h) Low profile filters to reduce getting caught on obstructions

i) Optional neck strap

j) Voice amplification system with radio interface capability. 


\section{Describe your likes or dislikes associated with storage pack.}

Most comments were positive. Suggestions centered around making the storage pack multifunctional with the ability to put it on the belt, front of web gear, side of web gear (such as under left arm by the belt), keep the radio pouch on the side, and include the extra pouch for maps and equipment. Negative responses were mainly that the storage pack got in the way while mounted on the front of the web gear, kept body heat in when held tight against the chest, was bulky, and it was too small for one of the of respirators used in the third year study.

5. Describe any changes you would make to the entire ensemble (hard hat, fire protective hood, storage pack, or web gear).
a) Hard hats require the ratchet style headliner to adjust size when wearing the respirator
b) Adjustable pack mounting system (belt, web gear,)
c) Less bulky mask allowing for smaller storage pack
d) Easier breathing when wearing the respirator (lower resistance)
e) Redesign hood for better fit over respirator and to improve peripheral vision.

6. What aspects of your job could you not perform while wearing the full-face air-purifyimg respirator?

Wearing the respirator changed a person's level of work intensity, thus limiting work activities to short periods of time at lower work rates. Difficult to use during a long progressive hose lay. Radio communication was almost impossible while wearing the respirator.

7. Do you have a routine physical fitness program that you perform.? Describe it. 
There were as many different physical fitness training programs as there were people responding to the questions. Most people who identified a personal physical fitness program with a portion of it being an aerobic work out indicated that full-face air-purifyimg respirator use was not a major problem. Those who were not in good physical shape had a much more negative evaluation of the use of the full-face air-purifyimg respirators. 


\section{CONCLUSIONS / RECOMMENDATIONS}

- With only a few exceptions the fire fighters' input during this test program indicated that a full-face air-purifyimg respirator was a useful tool that would improve their safety in fighting wildland fires.

- Most fire fighters felt that the use of a wildland respirator should not be mandatory at all times during fire-fighting operations. The wildland fire fighter, through training and field experience, should be given the option of donning and wearing the respirator as the situation warrants.

- A full-face air-purifyimg respirator with OV/AG HEPA was the cartridge of choice for use by the wildland fire fighters.

- Information collected from fire fighters wearing a full-face air-purifyimg respirator during their normal wildland fire responses indicated a reduced work rate. This reduced work rate will have to be considered when fire fighters use a respirator. However, work levels would be expected to significantly drop or even cease for fire fighters not wearing full face air purifying respirators when exposed to irritating concentrations of smoke emissions (short-term, acute effects).

- The importance of respirator training by qualified respirator personnel on an annual bases cannot be over stressed.

- A respiratory protection program established by $\mathrm{CDF}$ in accordance with CAL/OSHA and current ANSI standards will be required before respirators can be issued to wildland fire fighter personnel.

-A major component of the respirator program must address where and how the full-face air-purifyimg respirator is to be used. Special attention needs to be focused on emphasizing that these respirators don't replace self-contained breathing apparatus. At no time should these respirators be used for structural fire fighting. Clear responsibility needs to be assigned to the first line supervisors to assure the respirators are being used for the correct application. 
- A mandatory medical examination on a regular basis is necessary to monitor the physical conditions of fire fighters that are required to wear full-face air-purifyimg respirators.

- If wildland fire fighting personnel are issued air-purifying respirators the importance of also supplying them with a $\mathrm{CO}$ monitor/alarm instrument can not be over emphasized. The ability of these respirators to filter out the irritant smoke and allow a fire fighter to stay in a smoke environment longer will increase the potential for significant $\mathrm{CO}$ exposure. This potential for increased exposure to $\mathrm{CO}$ must be emphasized in the respirator training as well as the effects of $\mathrm{CO}$ exposure on the human body.

- The CO monitoring instrument should require little or no maintenance by the station crews. The instrument should be self-calibrating when exposed to a calibration gas, give an indication of the sensors remaining life span, have an audio alarm loud enough to hear during high noise levels around fire fighting equipment. It should have a visual display of the concentration of $\mathrm{CO}$. The sensor should last at least a year and should be easily maintained in the fire station by a qualified station crew member. There are instruments currently manufactured that fill these requirements in the $\$ 500.00$ to $\$ 1000.00$ range.

- CDF should consider a minimum physical fitness training program that each fire fighter undertakes on a scheduled frequency to maintain a minimum level of physical fitness. NFPA 1500 suggest that a physical fitness program be established to emphasize the general health benefits to the fire fighter as well as benefits to the fire department. The National Fire Academy suggests establishing a broad-base fitness committee including representatives from labor, management, recreation, emergency medical service personnel, the medical department, and a fitness expert.

- Information collected during the three-year testing program indicates that no current make of respirator meets all the needs of CDF wildland fire fighters. From the various findings and recommendations summarized in this report CDF 
can prepare a purchase specification for Wildland air-purifying respirators that addresses the major needs of the wildland fire fighter. Due to current respirator technology however, all of the items identified may not be available. Cost of the individual respirator will also determine the availability of various options.

Whatever respirator CDF selects must however address potential CO exposure by use of a separate monitor for each fire fighter or incorporate the $\mathrm{CO}$ monitor into the respirator. 


\section{References}

1. James S. Johnson, "Prototype Mask Protects Fire fighters," International Society for Respiratory Protection Journal, Fall (1990).

2. U.S. Code of Federal Regulations, 29 CFR 1910.134.

3. American National Standard for Respiratory Protection, ANSI Z88.2-1980.

4. California Environmental Regulations, Title 8, CCR 5155.

5. Hamilton, A. and H.L. Hardly, Industrial Toxicology, (Van Nostrand, NY, NY, 1974).

6. K.L. Foote, Determination of Toxic Material Penetrations for Wildland Respirator Filters, Lawrence Livermore National Laboratory, Livermore, CA, UCRL-LR-122560 (1996). 
3M Company

Occupational Health \& Safety

Products Division

Saint Paul, MN 55101

Survivair

3001 S. Susan Street

Santa Ana, CA 92704

MSA

P.O. Box 426

121 Gama Drive

RIDC Industrial Park

Pittsburgh, PA 15238

National Draeger, Inc

P.O. Box 120

Pittsburgh, PA 15230

Pro-Tech Respirators, Inc

P.O. Drawer 107

East Alexander Street

Buchanan, MI 49107

Scott Aviation

225 Erie Street

Lancaster, NY 14086

Wilson Safety Products

2nd \& Washington Streets

P.O. Box 622

Reading, PA 19603-0622

AO Safety

Cabot Safety Corporation

90 Mechanic St.

Southbridge, MA 01550 


\section{Appendix II \\ Prototype Wildland Fire Fighter Respirator Test Questionnaire 1991 ver.}

$\begin{array}{ll}\text { Date } & : 11 / 1991 \\ \text { Time } & : \\ \text { Fire ID : } \\ \text { User Initials }\end{array}$

Did you put it on?

Did you remove it at any time? To talk? To readjust it?

What type of task did you do while wearing the respirator? Chain saw, shoveling, polaski?

How was visibility?

Did you have any trouble seeing?

Did you have any trouble with the storage sack? with the mask in it or out?

Did the mask fog up?

How did it fit?

Was the mask comfortable to wear?

Did you have any trouble breathing?

Was the green light a distraction?

How many times did you notice the red alarm??? No times

1 time

2-4 times

5-10 times

Greater than 10 times

Did you have eye irritation while wearing the respirator?

After donning the respirator, did you still notice smoke odor? if so for how long?

Did the respirator get wet duing use and was its performance affected?

Did you notice any physical difference in yourself after using the respirator? (i.e. headaches,running nose?)

Was the wildland respirator a libility or an asset?

How many times did you use the wildland respirator?

How many times have you used aa self-contained breathing apparatus(SCBA)?

Additional Remarks: 


\section{Appendix III}

\section{Wildland Fire Fighter Respirator Test Questionnaire}

Date : $1 / 11993$ User Name:

(last,first)

Time :

Users Age:

Incident No.:

Users Experience :

Fire Station Location: Respirator Mfg. :

Cartridge type :

How does this compare to not wearing a respirator 1 better with resp 5 same as without resp 10 worse then without a resp

Did you put the respirator on? (YES / NO)

Did you remove it at any time? (Yes / No )

To talk?

To readjust it ?

What type of tasks did you do while wearing the respirator? Hiking, Chainsaw, MacBroom, McCloud?

*How was the visibility compare to not wearing a respirator? (scale 1 to 10)

Have you ever fought a similar fire without respirator protection? Yes No

Did you have any trouble with the storage pack?

With the mask in it or out?

*Did the mask fog up ( compare to normal eye protection?

How did the respirator fit?

Was the respirator comfortable to wear? scale 1 to 10

*Did you have any trouble breathing while wearing the respirator?

*Did you have any eye irritation while wearing the respirator?

After donning the respirator, did you still notice any smoke odor? ( YES / NO) If yes for how long ?

Did the respirator get wet during use and was its performance affected?

Did you notice any physical difference in yourself after using the respirator?

Wheezing, shortness of breath, noise or eye irritation, sputum production, cough, headaches 
How long did you wear the respirator (estimate time in minutes)?

Was the respirator a liability or an asset?

How many times have you used the respirator?

Did you change the respirator cartridge? Yes / NO (If Yes, explain why)

Was there any medical attention required at or after the response. (If Yes, explain)

If possible take blood pressure as soon as possible after peak period of exertion.

Additional Remarks : 


\section{Summary of Incident}

INCIDENT NO.

Date

Start time

Finish time

Location

Type of terrain :

Type of fire :

Type of attack :

Number on crew:

Pilot

Crew Captain

Crew Members :

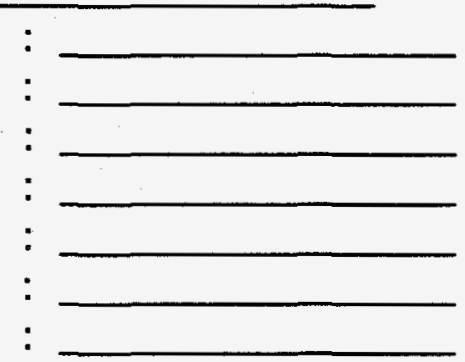

Filled out by :

Described by : 


\section{Questionnaire Instructions}

Fill out the questionnaire after each fire response.

Use Fire ID as assigned by the Dispatcher.

If answer to the question, "Did you use the respirator?" is "NO" then you have completed the questionnaire for that response.

Answer all question that are applicable to the fire response. If not applicable enter NA. 